\title{
Effect and control of path parameters on thickness distribution of cylindrical cups formed via multi-pass conventional spinning
}

\author{
Shiori Gondo ${ }^{1}$ (D) Hirohiko Arai ${ }^{1,2}$ (D)
}

Received: 9 May 2021 / Accepted: 22 November 2021 / Published online: 12 January 2022

(c) The Author(s) 2022

\begin{abstract}
In this study, an artificial neural network (ANN) model was constructed to investigate the relationship between the roller path parameters to form a cylindrical cup in multi-pass conventional spinning and the thickness distribution throughout the height of a workpiece. Furthermore, the path parameters that simultaneously realize multiple target values of the workpiece dimensions were calculated instantly by the iterative solution based on the constructed model. A systematic design of the path parameters for a constant thickness distribution was established as follows. First, the roller path was expressed using 12 parameters. Second, the workpieces were spun under various experimental conditions, which were determined by partial randomization of the orthogonal array based on the Taguchi method. Third, an ANN model was trained by considering seven path parameters as inputs and five forming result values as outputs (cup height, wall thickness at 25\%, 50\%, and $75 \%$ of the cup height, and residual path length). Finally, the path parameters required for realizing a constant thickness were determined using an ANN model with an iterative solution. Although several samples of the training dataset exhibited non-uniform thickness distributions, the workpieces that were spun under the parameters obtained via iteration exhibited a constant thickness distribution. The parameters responsible for stretching the material in the radial direction significantly affected the thickness distribution. The most influential parameter was the increment in the axial start position for each curved pass.
\end{abstract}

\section{Graphical abstract}
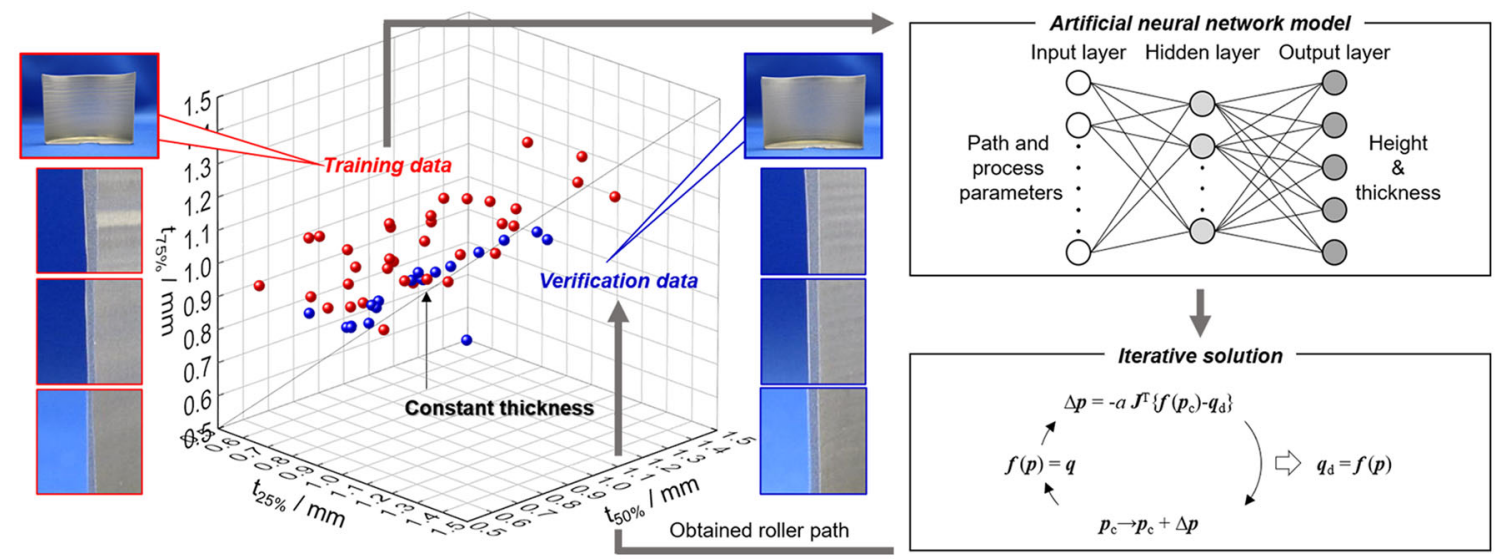

Keywords Metal spinning $\cdot$ Multi-pass conventional spinning $\cdot$ Artificial neural network $\cdot$ Iterative solution $\cdot$ Thickness

Shiori Gondo

shiori-gondo@aist.go.jp

Hirohiko Arai

h.arai@aist.go.jp
1 Advanced Manufacturing Research Institute, Department of Electronics and Manufacturing, National Institute of Advanced Industrial Science and Technology (AIST), Tsukuba East, 1-2-1 Namiki, Tsukuba, Ibaraki 305-8564, Japan 


\section{Abbreviations}

$\begin{array}{ll}n_{p} & \text { Number of curved passes } \\ p_{\text {feed }} & \text { Feed ratio } \\ r_{p} & \text { Residual path length } \\ R_{\text {round }} & \text { Roller nose radius } \\ r_{s} & \text { Mandrel speed } \\ x_{p 0} & \text { Axial position of blank surface } \\ x_{p \text {-end }} & \text { Axial end position of path } \\ x_{p \text {-start }} & \text { Axial start position of the first curved pass } \\ y_{p 0} & \text { Radial position of the cup side wall } \\ y_{p \text {-end }} & \text { Radial position of the path periphery } \\ \alpha_{0} & \text { Initial inclination angle } \\ \Delta x_{p} & \text { Increment in axial start position for each curved pass } \\ \theta_{1} & \text { Start angle of the arc pass } \\ \theta_{2} & \text { End angle of the arc pass }\end{array}$

\section{Introduction}

Metal spinning enables the formation of three-dimensional shapes, such as cups, from a rotating sheet metal material using a roller. The material can be deformed locally and incrementally using a small force. There are two types of metal spinning methods that can be used to form a workpiece from a metal sheet. One is shear spinning, and the other is conventional spinning. The workpiece is formed by moving a roller along the profile of a mandrel during shear spinning. During conventional spinning, the workpiece is formed gradually by moving the roller along the plural curve paths, as shown in Fig. 1. For conventional spinning, a complex configuration can be realized using only one mandrel with a final target shape, or, in some cases, no mandrel. The height and thickness of a workpiece change with varying roller paths, even if the same mandrel is used.

The values of various process parameters, such as the roller feed rate, mandrel speed, feed ratio, roller nose radius, roller diameter, and roller angle, should be determined to perform metal spinning. Moreover, for multi-pass conventional spinning in particular, the roller path has numerous degrees of freedom, including the number of passes, start position, inclination angle, length, and shape of each pass. Thus far, various types of pass shapes have been suggested, such as linear, second-order (concave and convex), and involute types, as well as a combination of these types. However, it is difficult to express the roller path using only a few parameters owing to their numerous degrees of freedom.

2 Daitoh Spinning Co. Ltd., 738-5 Nakano, Oura, Gunma 370-0603, Japan
The roller path and process parameters in metal spinning are hereinafter referred to as "path parameters." Wrinkling or fracturing of workpieces may occur when inappropriate path parameters are used. Although failure of the workpieces can be avoided, there are various challenges in achieving the desired thickness. Therefore, it is necessary to determine the appropriate parameters for controlling the thickness of the workpiece without failure.

To determine the appropriate process parameters, previous studies have investigated (1) the deformation mechanism of the workpieces during spinning using analytical and numerical calculations, and by observing the microstructure of the spun workpieces; and (2) the effect of the process parameters on the height, thickness, and spinnability (wrinkling and fracturing) of workpieces through experiments and numerical calculations, such as the finite element method (FEM) simulation.

\section{Deformation mechanism in metal spinning}

The findings from the deformation mechanisms in existing literature are summarized here. Hayama and Murota (1963) reported that the tensile strain in the radial direction and the compressive strain in the thickness direction occur over the corner of the mandrel in single conventional spinning. Quigley and Monaghan (2000) presented the strain state at the corner of the mandrel, under the roller, and at the flange in spherical conventional spinning. They observed that tensile strain in the radial direction, compressive strain in the thickness direction, and an extremely small circumferential strain occurred in all regions. However, this tendency declines toward the flange. Additionally, under the roller, compressive and tensile strains in the radial direction occurr on the roller and mandrel sides, respectively. Liu et al. (2002) described the same deformation mechanism in the multipass conventional spinning of a cup, as indicated by Quigley and Monaghan (2002). Xia et al. (2005) also presented the same mechanism as that in the conventional simple spinning of a cup. Wang and Long (2011a) clarified the strain states in the forward pass in multi-pass conventional spinning as follows: in the region between the clamped area by the backplate and the last point at which the workpiece is in contact with the mandrel, a large tensile strain in the radial direction and compressive strain in the circumferential direction occur on the roller and mandrel sides, respectively. In contrast, in the region between the last point at which the workpiece is in contact with the mandrel and the roller contact point, a large tensile strain in the radial direction and compressive strain in the circumferential direction occur on both the roller and mandrel sides, respectively. In general, the workpiece exhibits both the tensile strain in the radial direction and compressive strain in the circumferential direction; these strains cause a decrease and an increase in the 


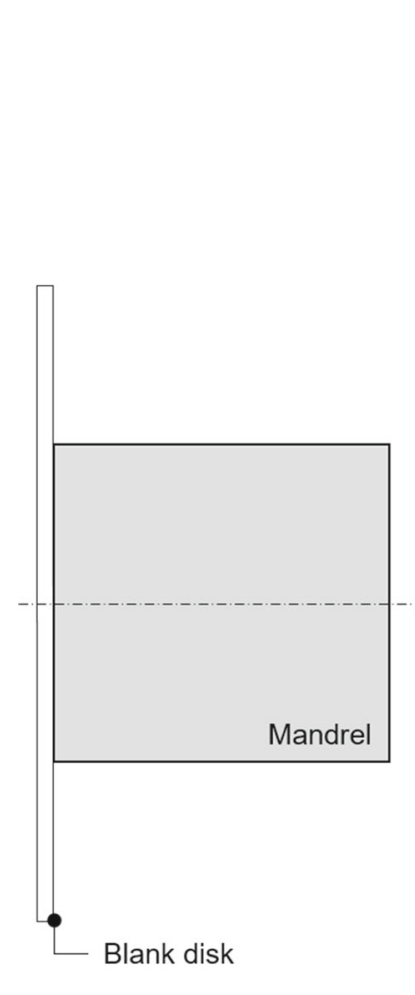

(a) Before spinning

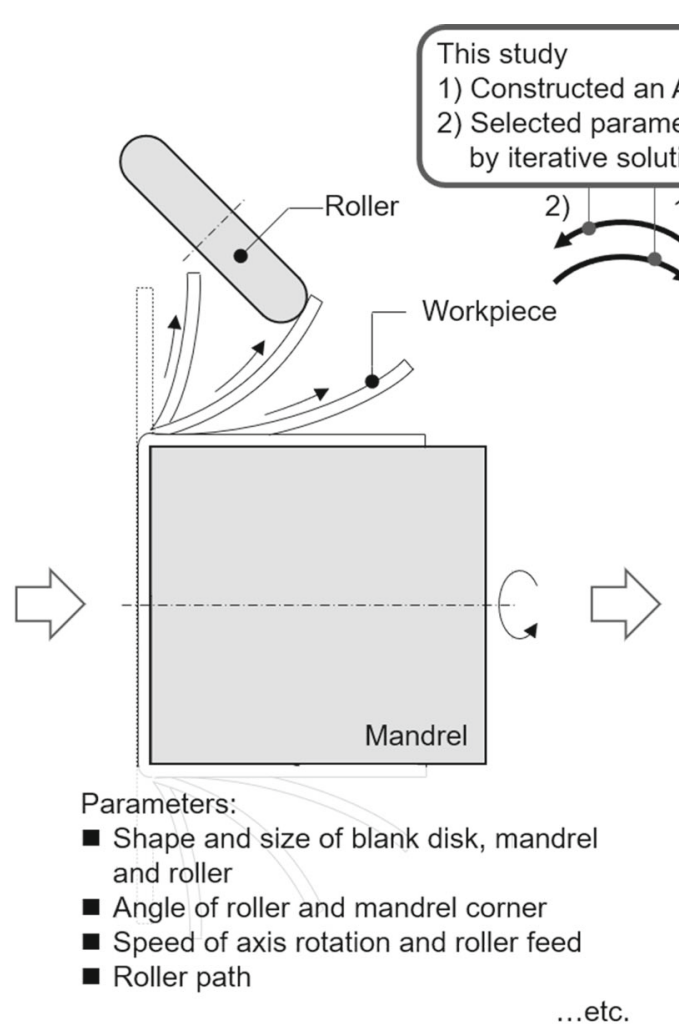

(b) During spinning netc.
Dimensions of workpiece:
- Height
- Thickness distribution
Spinnability
- Wrinkling
- Fracturing ...etc.

Fig. 1 Over views of conventional multi-pass spinning and approach used in this work. Conventional spinning involves following steps: (a), (b), and $(\mathbf{c})$

workpiece thickness, respectively. Furthermore, Wang and Long (2011a) suggested that the thickness of the workpiece decreases owing to the large tensile strain in the radial direction. Gondo et al. (2021) experimentally investigated the evolution of the strain state of spun workpieces after each pass during multi-pass conventional spinning, and established a relationship between the strain states and forming forces.

Similar to the strain state, Quigley and Monaghan (2001) and Sebastiani et al. (2007) reported that compressive and tensile stresses are produced on the roller and mandrel sides under the roller, respectively. Kleiner et al. (2002) clarified that the stress states occur in two regions, namely, the region between the mandrel corner and middle part of the flange, and the region in the vicinity of the flange. In the former region, the tensile stress in the radial direction increases during the roller passes, whereas the circumferential directional stress remains unchanged. In contrast, the circumferential compressive stress increases in the latter region. This tendency indicates the possibility of wrinkling. Wang and Long (2011b) presented the stress states in the forward path during multi-pass conventional spinning. In the region after the roller passes, that is, the region between the mandrel corner and the roller, a large tensile stress in the radial direction and compressive stress in the circumferential direction are produced. Meanwhile, in the region before the roller passes, that is, the region between the roller and flange, compressive stress primarily occurs in the circumferential direction. Moreover, the workpiece is found to be bent in three regions: at the mandrel corner, between the mandrel corner and roller, and under the roller. The direction of bending under the roller is opposite to that in the other two regions.

\section{Effects of process parameters on spinning results}

Several investigations have been conducted on the effects of the process parameters on the workpiece configuration and spinnability. Kalpakcioglu (1961) and Sebastiani et al. (2006) reported on the effect of the deviation in the sine law on the workpiece thickness during shear spinning. The workpieces spun by under-spinning and over-spinning exhibits nonuniform thickness distributions. El-Khabeery et al. (1991) studied the effect of the roller nose radius and roller feed rate on the workpiece thickness in conventional spinning. The workpiece exhibits a uniform thickness distribution when a large roller nose radius and a small roller feed rate were adopted. Zhan et al. (2006) reported on the effect of the feed ratio on the workpiece thickness during shear spinning. Although the wall angle deviates from the set value, the workpiece thickness becomes uniform with increasing feed ratio. However, Wang and Long (2013) indicated that the work- 
piece thickness remains unchanged even with an increasing feed ratio. Furthermore, Essa and Hartley (2009) reported that the workpiece thickness increases with increasing feed ratio in conventional spinning. Russo et al. (2021) reported on the spinning result of several artisans who manipulated a roller by relying on experience and skills. Russo et al. recorded the manual operation of the roller tool with the help of spinning artisans, and established certain rules to maintain the thickness in conventional spinning. They showed that the roller path configuration significantly influences the forming results, including the shape of the workpiece. Wang and Long (2011a) reported that the convex and concave roller paths maintains and decreases thickness, respectively.

Numerous studies have been conducted on wrinkling and fracturing. Hayama and Tago (1968) reported that wrinkling and fracturing occur when the corn angle of the mandrel is large and small, respectively. Kobayashi (1963) reported that a combination of a thick blank disk with a large mandrel diameter or a small blank diameter prevents the workpiece from wrinkling. Essa and Hartley (2010) also indicated that a small blank disk is effective in preventing wrinkling. In other words, both Kobayashi (1963) and Essa and Hartley (2010) recommended a small spinning ratio to prevent wrinkling, that is, the ratio of the initial to final blank diameter. Dörge (1955) concluded that wrinkling of the workpieces can be prevented using a large blank disk and roller nose radius, even if the workpiece is spun under a large spinning ratio. Xia et al. (2005), Essa and Hartley (2009), Wang and Long (2013), and Kong et al. (2017) concluded that wrinkling can be prevented by spinning under a small feed ratio. Xia et al. (2005) reported that a tradeoff exists between feed and spinning ratios. A small feed ratio and large spinning ratio result in fracturing, whereas a large feed ratio and small spinning ratio cause wrinkling. Chen et al. (2021) indicated that wrinkling at the flange can be avoided in workpieces with large strengthening coefficients and small Young's moduli.

In this way, investigations that focus on the configuration of the roller path are extremely limited, even though the roller path significantly influences the forming results, including the shape of the workpiece. In addition, previous works did not clarify the change in the workpiece shape when some process parameters (configurations of roller, blank disk, and mandrel and forming speed) are simultaneously varied. Furthermore, the process parameters should be adjusted when applying the research outcomes to actual industrial sites if the properties and configuration of the material are different from those mentioned in the literature. Thus, the selection of the parameters still relies on trial and error to realize the workpiece shape prescribed by the concrete target values. To address the aforementioned limitations, this study proposes a machine-learning model to control the workpiece thickness.

\section{Application of machine learning in metal forming}

Some applications of machine learning in metal forming include the predictions of springback in bending or laser forming, load in forging, strain in deep drawing, and forming force in incremental forming. The plastic behavior of metal materials has also been predicted based on their chemical compositions and microstructures.

Pathak et al. (2005) developed an artificial neural network (ANN) model based on 44 datasets to predict the load as the output, with sheet thickness, die radius, stress, strain, and springback as input variables. The prediction results of the ANN were consistent with the FEM simulation results. Kurtaran (2008) established an ANN model with the following input parameters: bending sheet thickness, bending radius, and bending angle, with the bend allowance being the output parameter. Baseri et al. (2012) predicted springback using sheet thickness, sheet orientation, and punch tip radius as input parameters. Jafari et al. (2015) constructed an ANN model to determine the springback, considering the die temperature, lower punch radius, step distance, step height, and die clearance as the input parameters, using an adaptive neuro-fuzzy inference system. The step distance and height were the configuration parameters for the lower punch. Trzepieciński and Lemu (2020) estimated springback using mechanical properties, material rolling direction, and bending angle as the input parameters in V-bending. Barletta et al. (2009) and Lambiase et al. (2016) predicted the bending angle during laser forming. Barletta et al. (2009) considered the power of the laser source, scan speed, and starting elastic deformation as input parameters. Moreover, Lambiase et al. (2016) adopted the laser power, scanning speed, cooling media, and number of irradiations as input parameters. Viswanathan et al. (2003) predicted springback using material properties, thickness, and friction conditions as input parameters during steel channel forming. Jamli and Farid (2019) reviewed the reports on the application examples of ANN for the prediction of springback, and indicated that the existing approach using ANN cannot incorporate all the factors affecting the analysis results. Srivastava et al. (2004) predicted the final forging load using the ram velocity, billet temperature, and friction coefficient. Poshal and Ganesan (2008) estimated the formability index, triaxial stress ratio, axial strain from preform densities, and different aspect ratios for the cold upsetting of sintered Al. Bingöl and Kılıçgedik (2018) predicted the forging load by angle, dimension ratio, friction coefficient, velocity, and temperature in hot metal forming using gene expression programming. Ashhab et al. (2014) estimated the equivalent plastic strain, contact ratio, and forming load based on the geometrical parameters of the synchronizer ring during its manufacture. Hussaini et al. (2014) predicted the thickness of workpiece cups in hot deep drawing using the temperature, drawing ratio, and distance 
from the center of the cup to the thickness-measured position. Alsamhan et al. (2019) predicted the forming load by employing the step size, tool diameter, sheet thickness, and feed rate as the input parameters for incremental forming. Hartmann et al. (2019) discussed the possibility of predicting the shape of metal sheet formed by incremental forming using multinodes ANN model. Nagargoje et al. (2021) reviewed artificial intelligence techniques applied to incremental forming. Mandal et al. (2007) estimated the average crystal grain size using the strain, strain rate, and temperature during dynamic recrystallization. Chi and Han (2019) predicted the strength and total elongation of the material, obtained by tensile testing using the testing speed, speed changes, and initial and final tensile speeds as input parameters. Yamanaka et al. (2020) predicted biaxial stress-strain curves using the $\{111\}$ pole figures of the material. Merayo et al. (2020) predicted the mechanical properties of the material, such as plastic behavior, yield strength, and maximum tensile strength, based on the chemical composition, tempers, and Brinell hardness.

Some researchers have employed machine learning for metal spinning. For instance, Belfiore et al. (2007) adopted a multilayer neural network with a unique structure for the prediction of surface failure in flow forming. Similarly, Jiang et al. (2008) predicted the rib height based on an ANN model established using the experimental results of rib-forming tubes via ball spinning.

Owing to their usefulness, many of the aforementioned studies have adapted ANNs. The ANN model can be easily built by applying the process parameters and results obtained in metal forming to the input and output layers, respectively. However, it is difficult to determine the input parameters corresponding to the process parameters that can realize the desired output values. Göbel et al. (2005) suggested analytical methods using a case-based reasoning and fuzzy-based model, avoiding failures such as wrinkling and fracturing during metal spinning. However, they were unable to achieve design specifications and produce workpieces according to their design. Therefore, there is a need for a systematic design that can easily determine the parameters required to realize the desired configurations. Furthermore, the roller path must be parameterized using certain variables to include various types of formable paths.

\section{Idea of this study}

This study investigates the relationship between the parameterized roller path and the results to realize workpieces with a constant thickness by employing machine-learning techniques.

First, the path parameters are represented by the input parameters $\boldsymbol{p}=\left(p_{1}, p_{2}, \ldots, p_{\mathrm{n}}\right)$. Similarly, the configuration of the workpieces is represented by the output parameters $\boldsymbol{q}=\left(q_{1}, q_{2}, \ldots, q_{\mathrm{m}}\right)$. The relationship between the input and output parameters is expressed by a multivariable vector function as follows:

$q=f(p)$

Second, the target output $\boldsymbol{q}_{\mathrm{d}}$ representing the target configuration is substituted in Eq. (1) as follows:

$q_{d}=f(p)$.

Then, the path parameter $\boldsymbol{p}$ that produces the target output $\boldsymbol{q}_{\mathrm{d}}$ is calculated by solving Eq. (2) using an iterative solution. This operation corresponds to determining the input parameters to realize multiple outputs.

In this study, the path parameters and workpiece configurations are represented by seven and five parameters, respectively. Thus, $\boldsymbol{p}=\left(p_{1}, p_{2}, \ldots, p_{7}\right)$ and $\boldsymbol{q}=\left(q_{1}, q_{2}, \ldots\right.$, $q_{5}$ ). The connection between the path parameters and workpiece configurations, the function $\boldsymbol{f}(\boldsymbol{p})$, is illustrated using the ANN model. The ANN model, in which path parameters are assigned to the input nodes, is easy to apply to real operations because the input values calculated by the iterative solution can be treated as concrete optimized values of the path parameters in actual spinning. Thus, the contribution of this study is a method for instantly and simultaneously calculating path parameters that realize multiple target values of the workpiece dimensions, using an iterative solution based on the constructed ANN model of the relationship between path parameters and workpiece shapes.

Therefore, the objectives of this study are to investigate (1) the applicability of ANN in metal spinning, (2) the effectiveness of an iterative solution to determine the path parameters under which the workpiece is formed to achieve the desired configuration, and (3) the effects of the path parameters on the thickness distribution.

\section{Methods}

The process to realize workpieces with a constant thickness are as follows.

1. Parameterizing the roller path (Sect. 3)

2. Acquiring data for training and validation (Sect. 4)

3. Designing the artificial neural network model (Sect. 5)

4. Selecting appropriate parameters using an iterative solution (Sect. 6)

Lastly, the effects of path parameters on thickness distribution were evaluated (Sect. Evaluation of the effects of path parameters on thickness of a workpiece). 

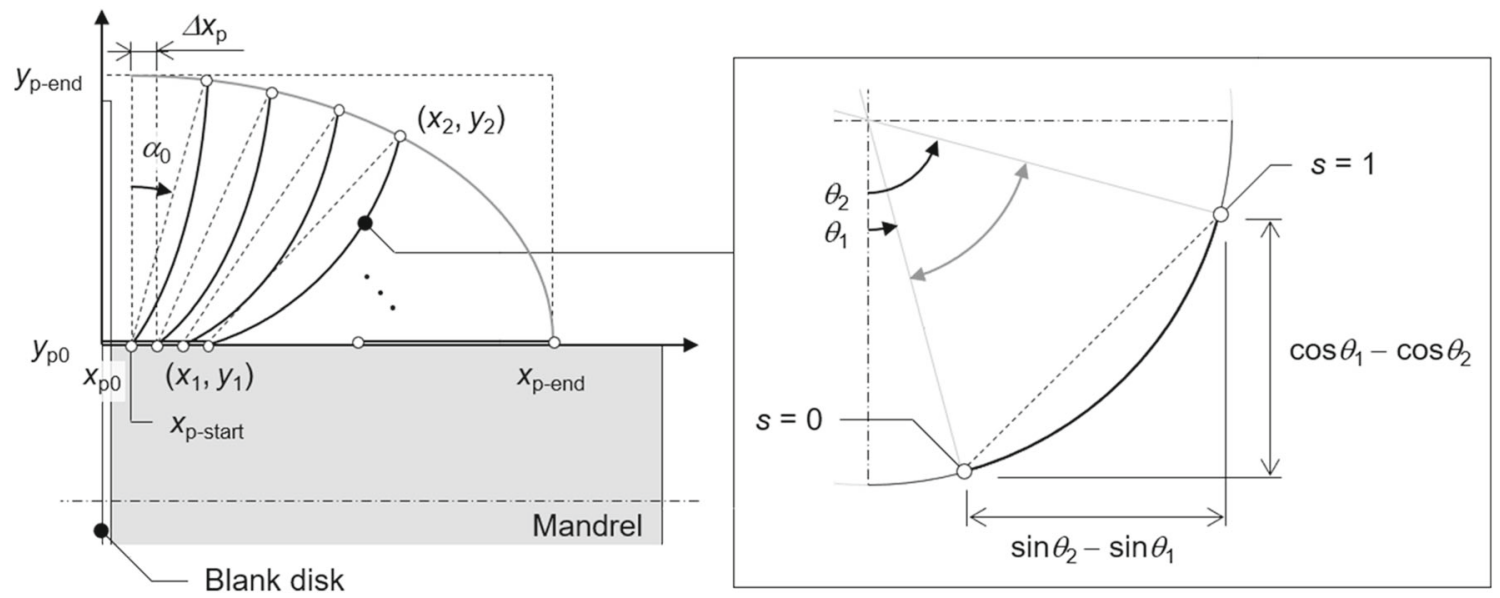

Fig. 2 Parameters composing roller path

\section{Parametrizing roller path}

The roller path for multi-pass conventional spinning was designed as proposed by Sugita and Arai (2015). The roller path consists of straight-line passes along the workpiece and curved passes in regions where the workpiece is not in contact with the mandrel, as illustrated in Fig. 2. The roller moves along a straight-line pass, pushing the material onto the mandrel. The roller then proceeds along a curved pass from the sidewall of the workpiece toward the edge. Subsequently, the roller leaves the workpiece and moves to the starting position of the next straight-line pass without touching the workpiece.

The path parameters depicted in Fig. 2 were $x_{\mathrm{p} 0}, x_{\mathrm{p} \text {-start }}$, $x_{\mathrm{p} \text {-end }}, \Delta x_{\mathrm{p}}, y_{\mathrm{p} 0}, y_{\mathrm{p} \text {-end }}, \alpha_{0}, n_{\mathrm{p}}, \theta_{1}$, and $\theta_{2}$; which represent the axial position of the blank surface, axial start position of the first curved pass, axial end position of the path, increment in axial start position for each curved pass, radial position of the cup side wall, radial position of the path periphery, initial inclination angle, number of curved passes, start angle of the arc pass, and end angle of the arc pass.

The origin of the path coordinate system was expressed as $\left(x_{\mathrm{p} 0}, y_{\mathrm{p} 0}\right)=(0,0)$. The start position of the first curved pass is represented by $\left(x_{\mathrm{p}-\mathrm{start}}, 0\right)$. The end position of each curved pass lies on a quarter-ellipse through $\left(x_{\mathrm{p} \text {-start }}, y_{\mathrm{p} \text {-end }}\right)$ and $\left(x_{\mathrm{p} \text {-end }}, 0\right)$, and the origin of the quarter-ellipse was $\left(x_{\mathrm{p} \text {-start }}\right.$, 0 ). The start position of each curved pass moved at a constant interval along the sidewall of the workpiece in the $x$ (axial) direction. The inclination angle between the start and end positions of the curved pass increases at a constant angle and reaches $\pi / 2$ in the final pass.

The curved pass is part of an elliptical arc and exhibits a concave shape. It is scaled from a reference circular arc of unit radius (Fig. 2, right) in the $x$ (axial) and $y$ (radial) directions. The curved pass is expressed as follows:

$\left\{\begin{array}{l}x=x_{1}+\left(x_{2}-x_{1}\right) \frac{\sin \left(\left(\theta_{2}-\theta_{1}\right) s+\theta_{1}\right)-\sin \theta_{1}}{\sin \theta_{2}-\sin \theta_{1}} \\ y=y_{1}+\left(y_{2}-y_{1}\right) \frac{\cos \theta_{1}-\cos \left(\left(\theta_{2}-\theta_{1}\right) s+\theta_{1}\right)}{\cos \theta_{1}-\cos \theta_{2}}\end{array}\right.$,

where the start and end positions of the curved pass are indicated by $\left(x_{1}, y_{1}\right)$ and $\left(x_{2}, y_{2}\right)$, respectively. The symbol $s$ represents the progress rate of each pass, $s=0$ at the start point, and $s=1$ at the end point of the pass. The other path parameters are expressed using two variables: feed ratio $p_{\text {feed }}$ and mandrel speed $r_{\mathrm{s}}$. The variable input parameters are $n_{\mathrm{p}}$, $x_{\mathrm{p} \text {-start }}, x_{\mathrm{p} \_ \text {end }}, y_{\mathrm{p} \text {-end }}, \alpha_{0}, \Delta x_{\mathrm{p}}$, and $p_{\text {feed }}$ in this study.

\section{Acquiring data for training and validation}

\section{Method of multi-pass conventional spinning}

An Al sheet (A1050-O) was used as the blank disk. The shape of the disk was similar to that of the CD. The diameters of the disk and center hole, and the thickness of the $\mathrm{Al}$ sheet were 150,20 , and $1.49 \mathrm{~mm}$, respectively. The chemical composition of the $\mathrm{Al}$ sheet was Al-0.1Si-0.27Fe-0.02Ti mass\%.

The roller was made of SKD11 alloy tool steel with a $70 \mathrm{~mm}$ diameter and $8 \mathrm{~mm}$ nose radius. It was equipped with a roller holder inclined at $45^{\circ}$ against the mandrel axis. The mandrel was made of quenched $0.45 \%$ carbon steel with an outer diameter of $85 \mathrm{~mm}$. For the training and validation data, the path parameters ranged as follows: $13<n_{\mathrm{p}}<26,0<x_{\mathrm{p} \text {-start }}$ $<8,57.9<x_{\mathrm{p} \text {-end }}<97.8,24<y_{\mathrm{p} \text {-end }}<34,0<\alpha_{0}<20, \Delta x_{\mathrm{p}}=$ $b\left(x_{\mathrm{p} \text {-end }}-x_{\mathrm{p} \text {-start }}\right) / n_{\mathrm{p}},(0<b<1), 0.8<p_{\text {feed }}<2.4, x_{\mathrm{p} 0}=0$, $y_{\mathrm{p} 0}=0, r_{\mathrm{s}}=180, \theta_{1}=10$, and $\theta_{2}=70$. The parameter ranges were determined based on pre-experiments in previous studies (Gondo et al., 2020, 2021). Specific values of 
the path parameters used in the experiments are shown in the Excel file provided with the Supplementary Materials. The path parameters for the training data were determined using the partial randomization of the Taguchi orthogonal array. The Appendix presents the improvement in the generalization capability of the ANN by combining the orthogonal array of the Taguchi method and the random offset. The path parameters were randomly assigned to the validation data. A total of 18 training and 18 validation datasets were obtained from the spinning experiments and are referred to as groups A and B, respectively. After spinning, the height of cup $h$ from the bottom was measured using a height gauge. The measurement points were $0^{\circ}$ and $180^{\circ}$ from the rolling direction in the blank disks. The thicknesses $t_{25 \%}, t_{50 \%}$, and $t_{75} \%$ were measured using a micrometer.

\section{Spinning results for training and validation}

Most of the workpieces were formed into cups without failure using the training and validation data parameters. Workpiece fracture during spinning occurred in only one sample, and no wrinkling was observed. Thus, the validation data (group B) contained 17 datasets.

Figure 3 illustrates the three-dimensional (3D) diagram and two-dimensional (2D) diagrams for the thicknesses $t_{25} \%$, $t_{50 \%}$, and $t_{75 \%}$ of the training (red points) and validation data (green points). Almost all samples exhibited a non-uniform thickness distribution in the height direction, and the plots were at a distance from the straight line, indicating a constant thickness $t_{25} \%=t_{50 \%}=t_{75 \%}$.

\section{Designing artificial neural network model}

\section{Structure of artificial neural network model}

An ANN is adopted to predict the output parameters corresponding to the input parameters. A multilayer perceptron (MLP), which represents the typical architecture of an ANN and can model any nonlinear function, is adopted herein to approximate the multivariable vector function to calculate the output parameters. The MLP consists of input, hidden, and output layers. Each layer is composed of multiple nodes. Each node in the hidden and output layers is provided with the inputs from each node in the previous layer, and a nonlinear function is calculated using the weighted sum as the output. This function is referred to as an activation function. A sigmoid function is generally used as an activation function. In the supervised learning of the MLP, the weighted coefficient between nodes is adjusted based on the results obtained from multiple training datasets. In other words, the iterative calculation for adjusting the weight is performed such that the prediction output of the MLP for the sample input $\boldsymbol{p}$ con- verges to the sample output $\boldsymbol{q}$. That is, it can be said that MLP is suitable for the iterative solution. This study adopted a back-propagation algorithm, which is generally used for supervised learning.

The ensemble learning method was also used to improve the generalization capability of the ANN. Ensemble learning improves the prediction capability for untrained datasets by training multiple predictors, such as ANNs, independently, and unifying the training results (Hansen \& Salamon, 1990). Bagging (Breiman, 1996) and boosting (Freund \& Schapire, 1997) are the major techniques used in ensemble learning. In the bagging method, different sets of training data are selected from all the data; the multiple predictors are trained by the selected datasets in parallel, and the results are unified by averaging them. In contrast, the predictors are sequentially trained using the boosting method. The training datum with a large error is weighted to be prioritized in training the next predictor. This study adopts the algorithm proposed by Urata et al. (2001), wherein the adaptive boosting method, a typical boosting method, is applied to the regression problem. It is assumed that the unified predictor consists of $u$-ANNs, which are trained using U-training data. The absolute value of the training error for the $k$-th training datum after the $v$-th ANN training is represented as $\left|e_{v k}\right|$. The frequency of training is adjusted such that the training probability of the $k$-th training datum for the $(v+1)$-th ANN becomes $\left|e_{v k}\right| / \sum_{j=1}^{U}$ $\left|e_{v j}\right|$. Training of the data with a large error is repeated more frequently than for those with a small error. After completion of the training, the prediction $\hat{q}$ by unifying the outputs of the ANNs was calculated using Eq. (4). The symbol $\hat{q}_{v}$ represents the prediction using the $v$-th ANN. The prediction $\hat{q}$ is the average of $\hat{q}_{v}$ weighted by the inverse of the total absolute errors.

$\hat{q}=\sum_{v=1}^{u} \frac{\left(1 / \sum_{k=1}^{U}\left|e_{v k}\right|\right)}{\sum_{l=1}^{u}\left(1 / \sum_{k=1}^{U}\left|e_{l k}\right|\right)} \hat{q}_{v}$,

Herein, the unified predictor is built from 10 ANNs.

\section{Construction of individual model}

Individual models that predict height $h$ and thicknesses $t_{25 \%}$, $t_{50 \%}$, and $t_{75 \%}$ were developed using the training data. The hidden layer contained seven nodes. When the axial length of the roller path was too short compared to the cup height, the remaining material formed a flange at the edge of the workpiece. In contrast, if the length of the path was too long, thinning occurred at the workpiece edge when the roller went over the edge. To avoid the occurrence of flange and prevent the workpiece from sticking to the mandrel owing to the thinning of the workpiece, the residual path length $r_{\mathrm{p}}$ was 
Fig. 3. $2 \mathrm{D}$ and $3 \mathrm{D}$ scatter plots for $t_{25}, t_{50 \%}$, and $t_{75 \%}$ of workpieces for training (group A: red plots) and validation data (group B: green plots) (Color figure online)
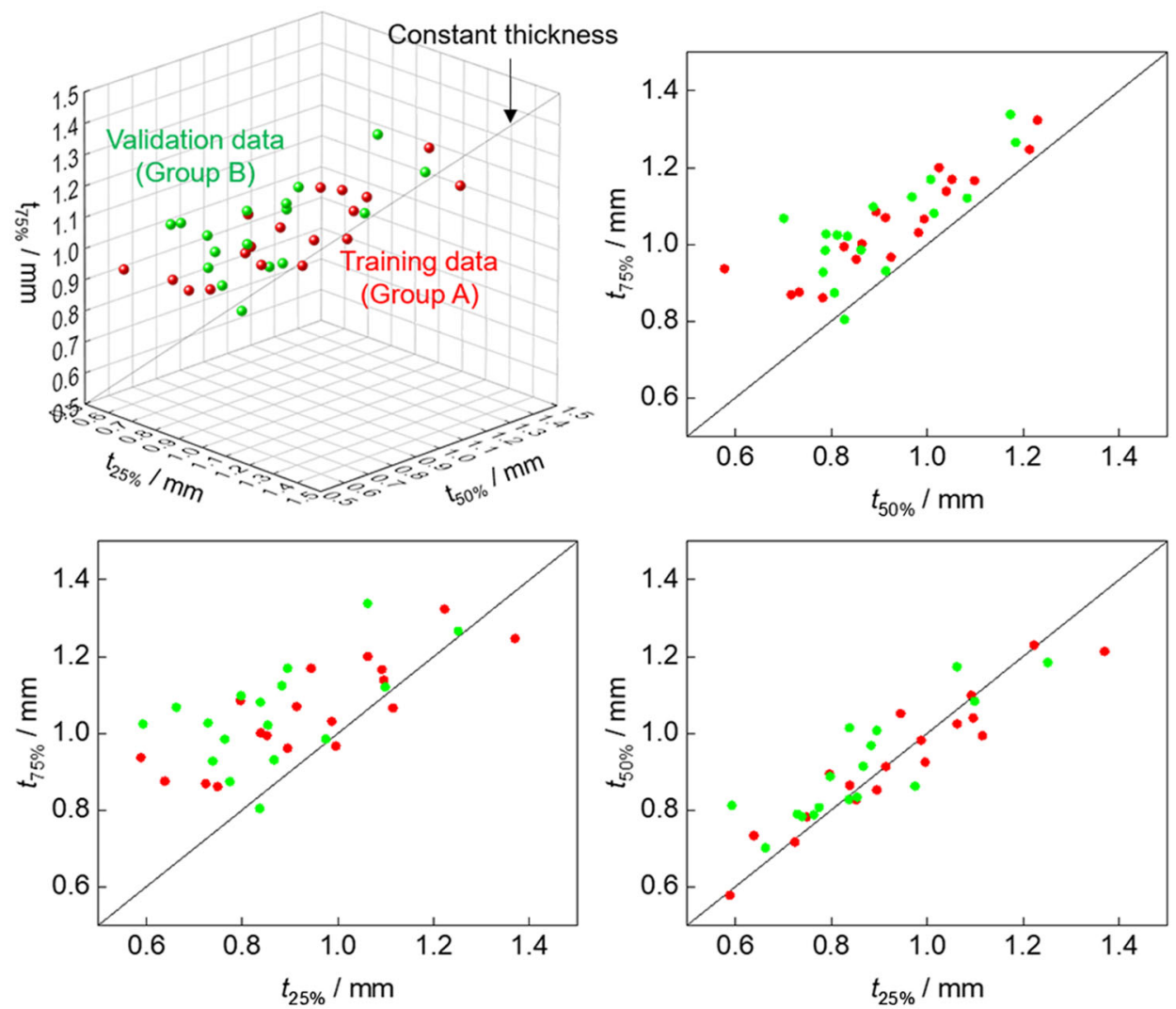

introduced in the output layer in each model and calculated using the following equation:

$r_{p}=x_{\mathrm{p}-\mathrm{end}}-\left(h+R_{\text {round }}\right)$

where $R_{\text {round }}$ indicates the roller nose radius.

The accuracy of each model was evaluated using the validation data. The path parameters of the validation data were applied to the proposed ANN model to predict the workpiece configuration. As mentioned previously, the same path parameters were used to spin the real workpieces. The predictions from the ANN model were compared to the measured results of the workpiece configuration. Furthermore, the root mean square error (RMSE) and coefficient of determination $\left(R^{2}\right)$ for each model were calculated. The RMSE is close to 0 , and $R^{2}$ is close to 1 when the ANN model has a high accuracy. The parameters $q_{j}, \bar{q}, \hat{q}_{j}$, and $N$ denote the measured values for the validation data, average $q_{j}$, prediction value, and number of validation data, respectively (Table 1).

$\mathrm{RMSE}=\sqrt{\frac{1}{N} \sum_{j=1}^{N}\left(q_{j}-\hat{q}_{j}\right)^{2}}$
$R^{2}=1-\frac{\sum_{j=1}^{N}\left(q_{j}-\hat{q}_{j}\right)^{2}}{\sum_{j=1}^{N}\left(q_{j}-\bar{q}\right)^{2}}$,
Table 1 Chemical composition of $\mathrm{Al}$ sheet (mass\%)

\begin{tabular}{llll}
\hline $\mathrm{Si}$ & $\mathrm{Fe}$ & $\mathrm{Ti}$ & $\mathrm{Al}$ \\
\hline 0.1 & 0.27 & 0.02 & $\mathrm{Bal}$ \\
\hline
\end{tabular}

\section{Accuracy of individual predictor models}

Figure 4 depicts the comparison between the validation data and prediction data obtained from the models of height $h$ and thicknesses $t_{25 \%}, t_{50 \%}$, and $t_{75 \%}$. The validation and prediction data for $h$ and $t_{50 \%}$ indicated good agreement. The prediction data corresponded with the validation data when $t_{25 \%}$ and $t_{75 \%}$ were greater than 0.7 and $0.9 \mathrm{~mm}$, respectively. By contrast, the prediction data was larger than the validation data when $t_{25 \%}$ and $t_{75 \%}$ were less than 0.6 and $0.8 \mathrm{~mm}$, respectively. Table 2 lists the RMSE and $R^{2}$ values of each model. The RMSE values for height $h$ and thicknesses $t_{25 \%}, t_{50 \%}$, and $t_{75 \%}$ were less than 3 and $0.1 \mathrm{~mm}$, respectively, whereas their $R^{2}$ values were greater than 0.7 . In this way, the individual models exhibited small RMSE and large $R^{2}$ values, implying that the prediction values obtained from the individual models were in good agreement with the validation values. Thus, the relationship between the path parameters in multi-pass conventional spinning and the spun workpiece configuration can be appropriately modeled using ANNs. 
Fig. 4 Comparison between validation and prediction values for a height $h, \mathbf{b} t_{25 \%}, \mathbf{c} t_{50 \%}$, and $\mathbf{d} t_{75 \%}$ for individual models (a)

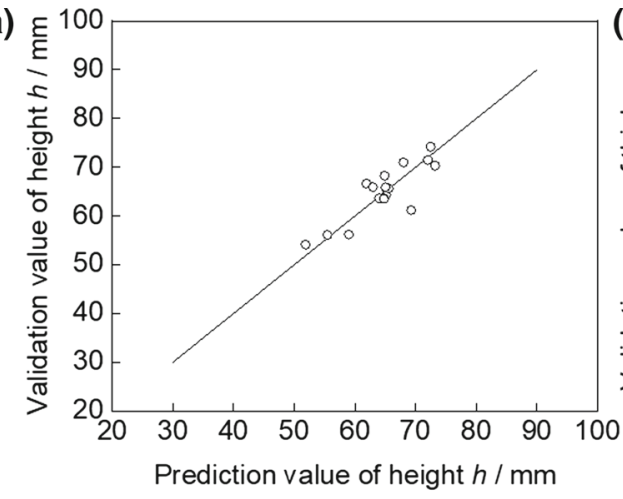

(c)

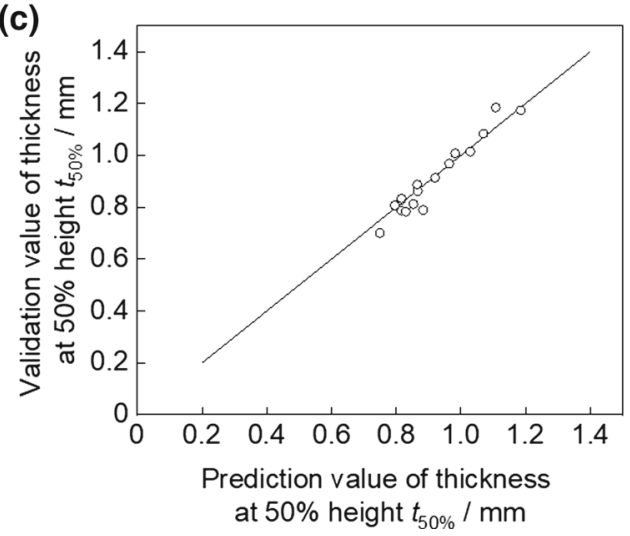

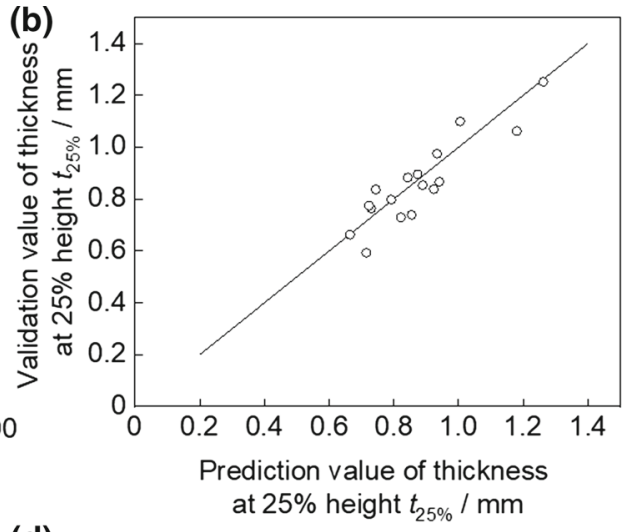

(d)

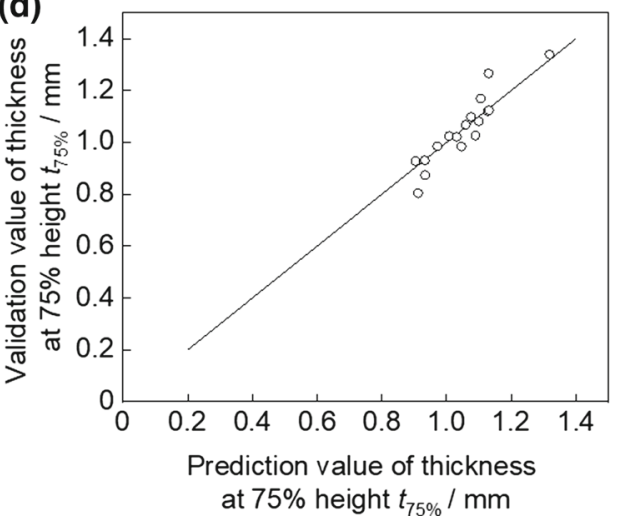

Table 2 RMSE and $R^{2}$ of individual models

\begin{tabular}{lllll}
\hline \multirow{5}{*}{ Height } & Thickness & & \\
\cline { 3 - 5 } & & At 25\% height & At 50\% height & At 75\% height \\
\hline RMSE & 2.93 & 0.07 & 0.04 & 0.05 \\
$R^{2}$ & 0.71 & 0.79 & 0.93 & 0.83 \\
\hline
\end{tabular}

\section{Selecting appropriate parameters using iterative solution}

\section{Iterative solution method}

For the relationship between the input and output parameters $\boldsymbol{q}=\boldsymbol{f}(\boldsymbol{p})$, the input $\boldsymbol{p}$ is solved via iteration based on gradient descent to calculate the parameter $\boldsymbol{p}$ that satisfies $\boldsymbol{q}_{\mathrm{d}}=\boldsymbol{f}(\boldsymbol{p})$. The Jacobian matrix of the function $\boldsymbol{f}(\boldsymbol{p})$ is defined by Eq. (8). The element $J_{\mathrm{jk}}$ of the Jacobian matrix $\boldsymbol{J}$ can be calculated by numerical differentiation, as shown in Eq. (9), using the element $p_{\mathrm{k}}$ of vector $p$, and a small value $\varepsilon$.

$\boldsymbol{J}(\boldsymbol{p})=\frac{\partial \boldsymbol{q}}{\partial \boldsymbol{p}}=\frac{\partial \boldsymbol{f}(\boldsymbol{p})}{\partial \boldsymbol{p}}$

$$
\begin{aligned}
J_{j k} & =\frac{\partial f_{j}(p)}{\partial p_{k}} \\
& \cong \frac{f_{j}\left(p_{1}, \ldots, p_{k}+\varepsilon, \ldots, p_{m}\right)-f_{j}\left(p_{1}, \ldots, p_{k}-\varepsilon, \ldots, p_{m}\right)}{2 \varepsilon}
\end{aligned}
$$

The difference between the output of the predictor under the current input $\boldsymbol{p}_{\mathrm{c}}$ and target output $\boldsymbol{q}_{\mathrm{d}}$ is represented as $\boldsymbol{e}=$ $\boldsymbol{f}\left(\boldsymbol{p}_{\mathrm{c}}\right)-\boldsymbol{q}_{\mathrm{d}}$. The correction vector $\Delta \boldsymbol{p}$ is calculated using the transpose of the Jacobian matrix $\boldsymbol{J}^{\mathrm{T}}$, as shown in Eq. (10), where $a$ is a constant.

$\Delta \boldsymbol{p}=-a \boldsymbol{J}^{\mathrm{T}} \boldsymbol{e}$

The column vector of the transposed Jacobian matrix $\boldsymbol{J}^{\mathrm{T}}$ represents the maximum gradient direction of each element of $\boldsymbol{q}$. Thus, the correction vector $\Delta \boldsymbol{p}$ is a combination of the change in $\boldsymbol{p}$ in the direction that each element of the error $\boldsymbol{e}$ approaches zero weighted by each element value. The current value of the input is updated using $\Delta \boldsymbol{p}$ as $\boldsymbol{p}_{\mathrm{c}} \rightarrow \boldsymbol{p}_{\mathrm{c}}+\Delta \boldsymbol{p}$. The parameter $\boldsymbol{p}$ that satisfies $\boldsymbol{q}_{\mathrm{d}}=\boldsymbol{f}(\boldsymbol{p})$ is calculated by repeating the previous calculation until the error $\boldsymbol{e}$ becomes sufficiently small. When vector $\boldsymbol{p}$ has $n$ elements, it is necessary to perform the calculation of $\boldsymbol{f}(\boldsymbol{p}), 2 n+1$ times per iteration. It is possible to determine the optimized path parameters in a very short time by spinning under several path parameters, con- 
Fig. 5 Comparison between target and prediction values of height $h$ and thickness $t_{25 \%}$, $t_{50 \%}$, and $t_{75 \%}$ for inclusive model (a)

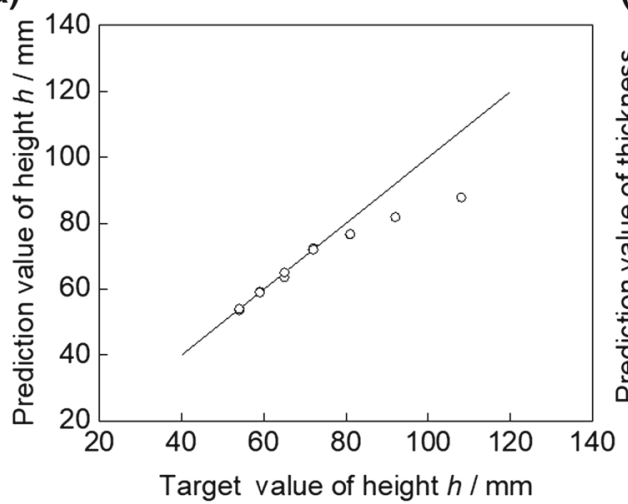

(c)

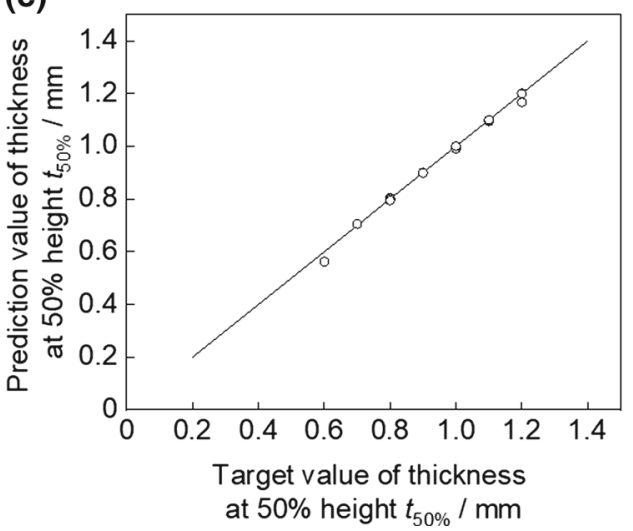

(b)

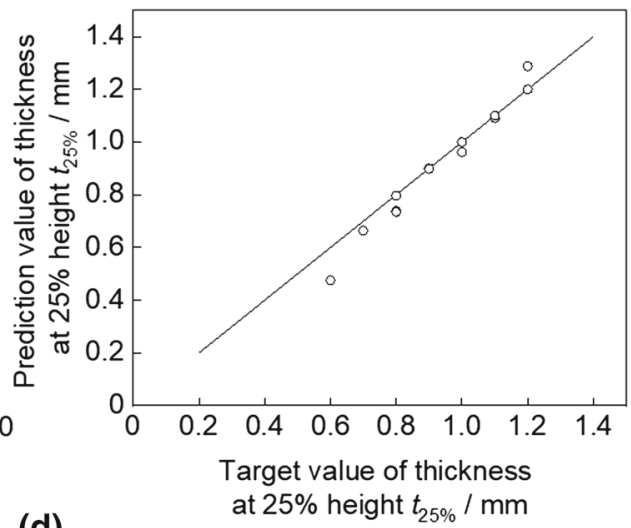

(d)

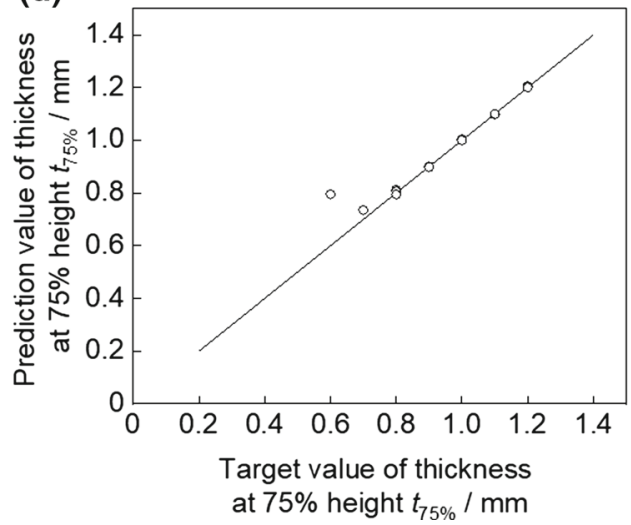

structing an ANN model, and applying an iterative solution; rather than by analyzing numerical simulations under numerous process conditions and searching for analysis conditions under which prediction values were the closest to the target values, because the numerical simulation of metal spinning takes too much time. Asshab et al. (2012) who performed the optimizing process parameters in deep drawing-extrusion combined process indicated the time consumption of numerical simulations.

\section{Construction of inclusive model and iterative calculations}

The inclusive model for predicting the height $h$ and thicknesses $t_{25 \%}, t_{50 \%}$, and $t_{75 \%}$ were constructed simultaneously using the training data (group A) and validation data (group B). In the inclusive model, the training data indicate the data of groups A and B. Similar to the individual models, the output layer included the residual path length.

The solution path parameters, that is, the input values to obtain the target values, were calculated using a combination of the above model and an iterative solution. The ranges of the input and output values were normalized in the iterative solution. The coefficient $a$ in Eq. (10) was 1. The allowable error was 0.02 . The minimum and maximum number of iter- ations were 4000 and 10,000, respectively. The initial input values for the iterative solution were selected from the path parameters of the training and validation datasets. The target values of the thickness were constant and determined by considering the thickness of the training and validation data. The target height was calculated from the target thickness by assuming a constant workpiece volume. The initial input and target values are presented in the supplementary material as an Excel file. The prediction data for height and thickness under the solution parameters were obtained. Target values were compared to the prediction values. Thereafter, 22 workpieces were spun under the solution parameters, and their height and thickness were measured as described in Sect. 2.2.2. These data are referred to as verification data and regard to as group C. When multiple sets of solution parameters had a similar combination of input values, they were merged into a single sample. The specific values of the path parameters are presented in the Supplementary Material. The verification data were compared to the target height and thickness values.

\section{Effectiveness of iterative solution}

Figure 5 depicts the target and prediction values of $h, t_{25} \%$, $t_{50 \%}$, and $t_{75 \%}$. The prediction values of $h, t_{25 \%}, t_{50 \%}$, and 

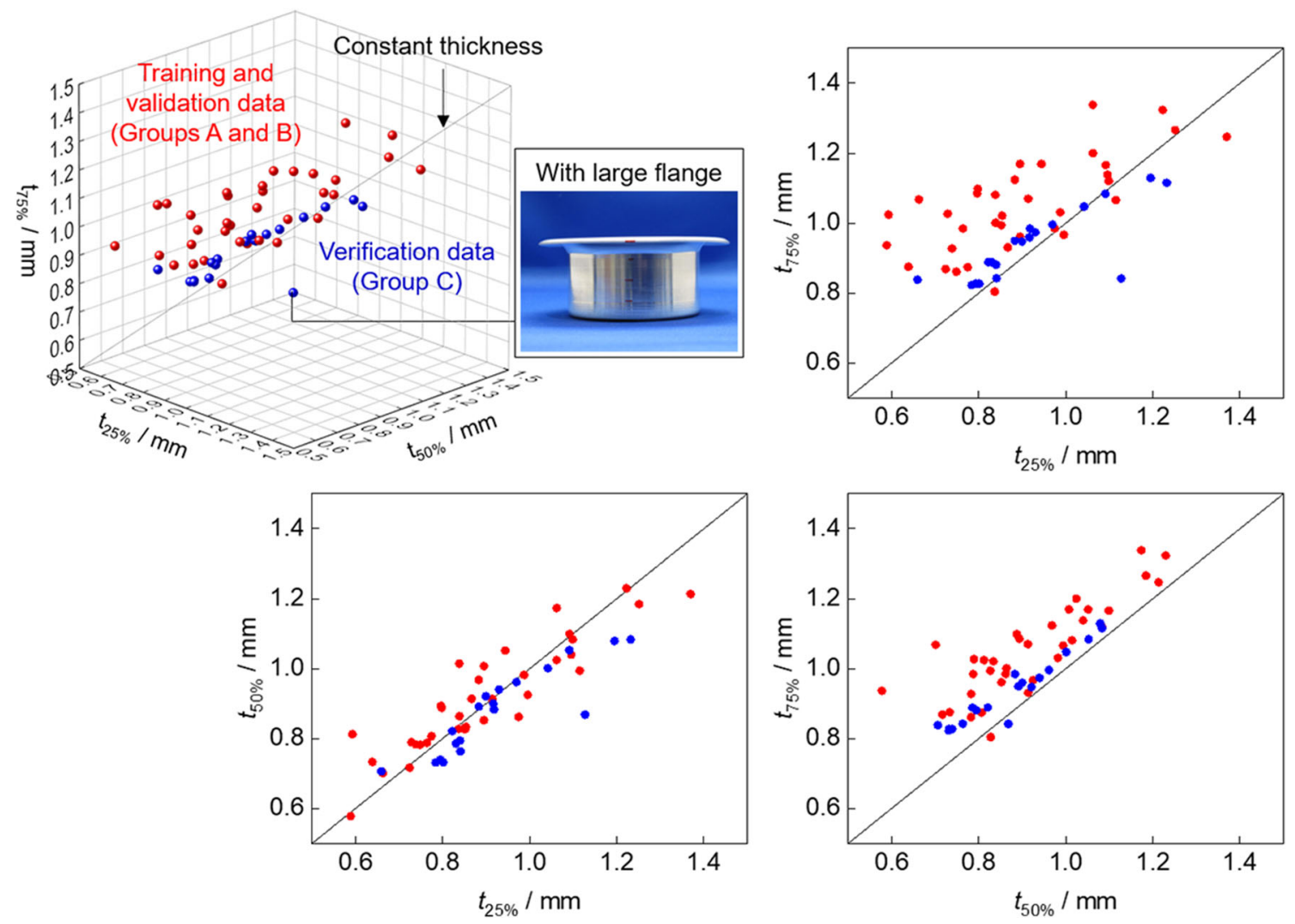

Fig. 6. $2 \mathrm{D}$ and 3D scatter plots for thickness $t_{25}, t_{50 \%}$, and $t_{75 \%}$ of workpieces for training data (group A and B: red plots) and verification data (group C: blue plots) (Color figure online)

$t_{75 \%}$ were calculated with RMSE of 4.99, $0.045,0.011$, and 0.035 , respectively. Under large height and small thickness conditions, the prediction values of $h$ and $t_{25 \%}$ were smaller than the target values of $h$ and $t_{25 \%}$, whereas the prediction values of $t_{75 \%}$ were larger than the target values of $t_{75} \%$. When the thickness was greater than $0.8 \mathrm{~mm}$, the prediction values of $h, t_{25} \%, t_{50 \%}$, and $t_{75 \%}$ corresponded well with the target values of $h, t_{25 \%}, t_{50 \%}$, and $t_{75 \%}$, respectively.

Figure 6 depicts the 2D and 3D scatter plots of the workpiece thickness for the verification data (group C) and training data (groups A and B). The workpieces of group $\mathrm{C}$ were spun using the solution parameters calculated using the iterative solution. It was observed that the verification data were closer to the straight line, indicating a constant thickness, that is, $t_{25 \%}=t_{50 \%}=t_{75 \%}$, in comparison with the training data. Consequently, the thickness distribution became more uniform compared to the training data. However, three samples of target shapes with a large height and small thickness fractured during spinning. The workpiece whose plot was distant from the constant thickness straight line had a large flange, as shown in Fig. 6. Figure 7 shows typical examples of spun workpieces. The forming results using the iterative solution, as shown in sample c in Fig. 7, exhibited an almost constant thickness distribution except near the cup edge.

Figure 8 depicts the comparison between the target and measured verification values of $h, t_{25 \%}, t_{50 \%}$, and $t_{75 \%}$. The RMSE of $h, t_{25}, t_{50 \%}$, and $t_{75 \%}$ were $1.87,0.086,0.013$, 0.094 , respectively. In particular, the measured verification values of $h$ and $t_{75 \%}$ corresponded well with the target values of $h$ and $t_{75 \%}$. The measured verification values of $t_{25 \%}$ and $t_{50 \%}$ corresponded suitably with the target values, although they were slightly smaller than the target values.

\section{Control of thickness using ANN and iterative solution}

In the inclusive model, the prediction data obtained under the input parameters solved via iteration indicated the possibility of simultaneous control of the height and thickness, as shown in Fig. 5. The measured verification data revealed that the iterative solution could systematically be used to determine the appropriate path parameters (Fig. 8). Thus, this study succeeded in controlling the constant thickness distribution using an iterative solution, even when the training data in the ANN model had a non-uniform thickness distribution of the cylindrical cup. In the case of workpieces with 

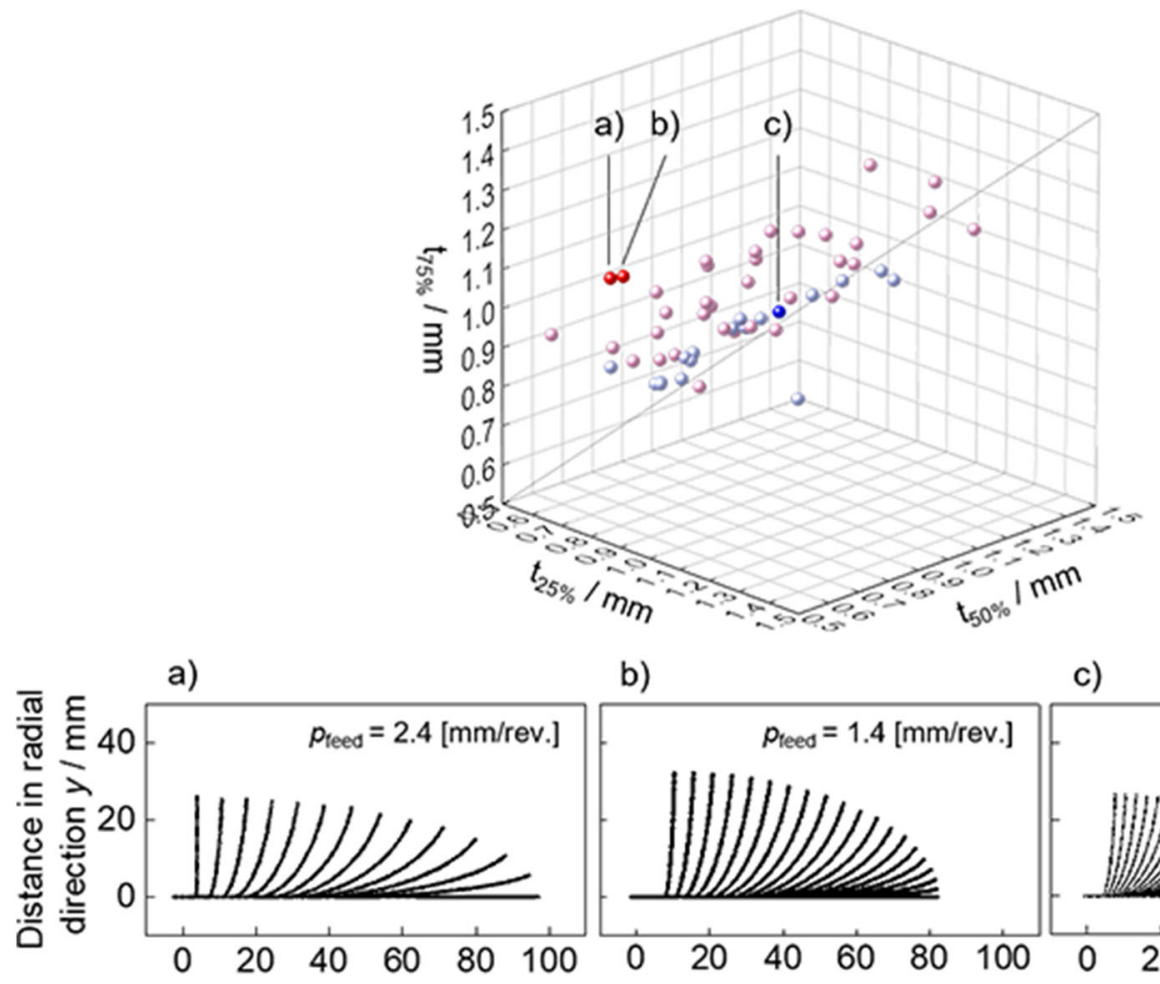

b)

c)
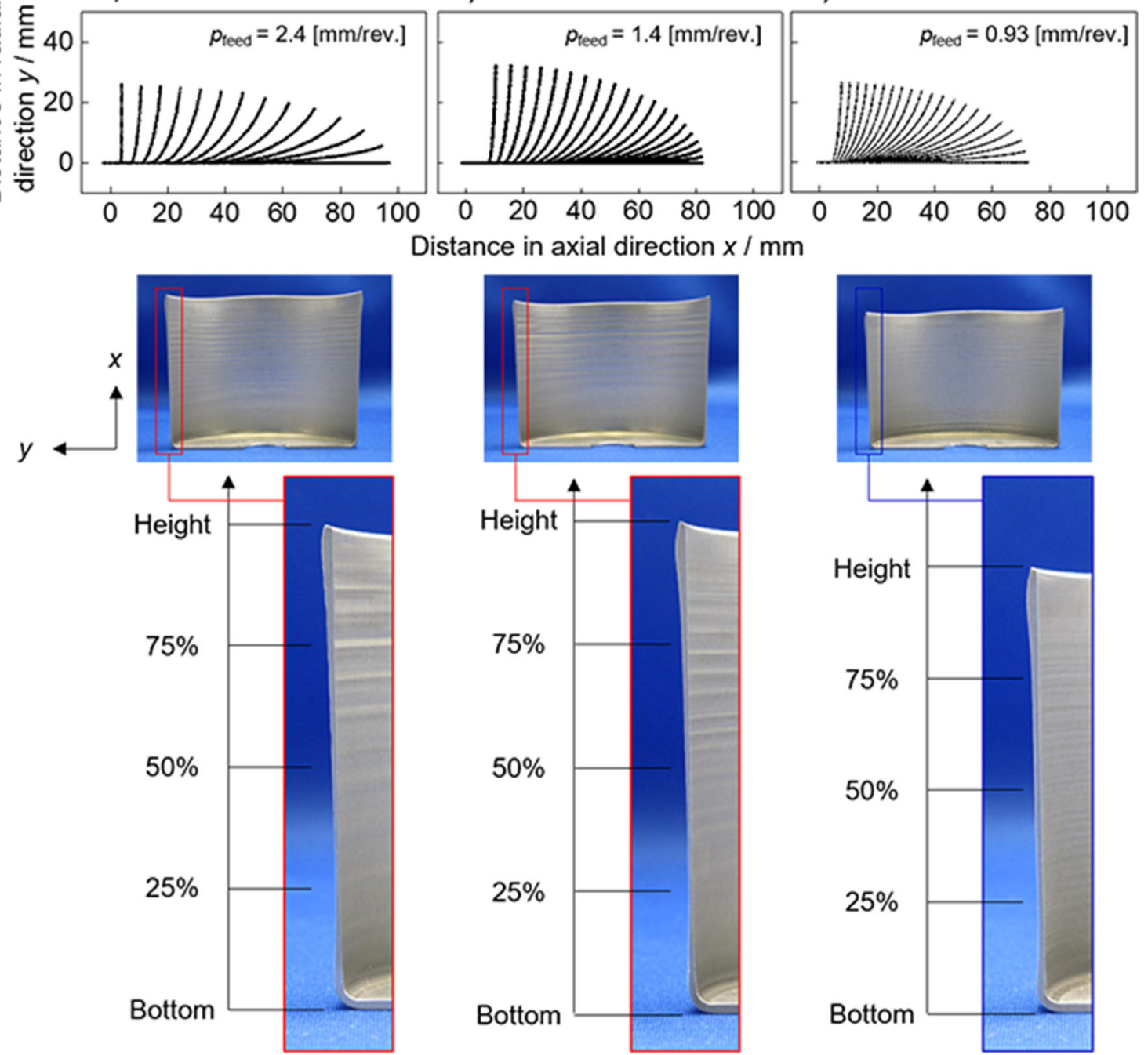

Fig. 7 Roller paths and longitudinal sections for sample examples: a and $\mathbf{b}$ (training), and $\mathbf{c}$ (verification data) 
Fig. 8 Comparison between target and verification values of height $h$ and thickness $t_{25 \%}$, $t_{50 \%}$, and $t_{75 \%}$ for inclusive model (a)

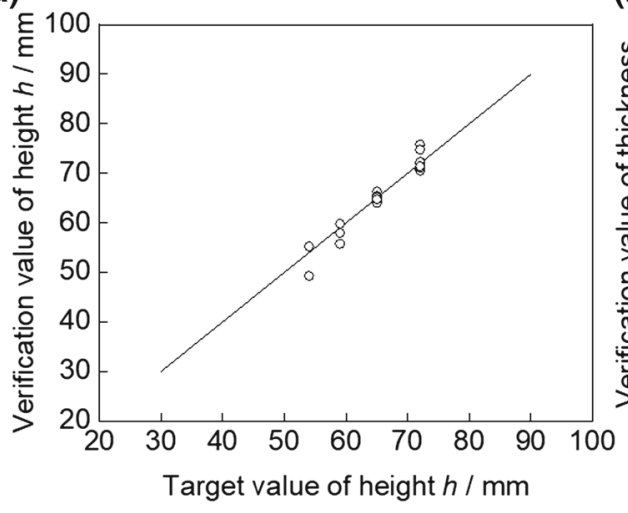

(c)

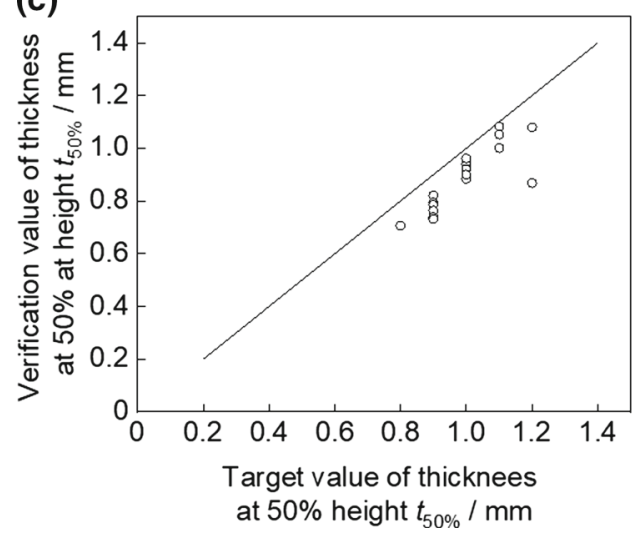

(b)

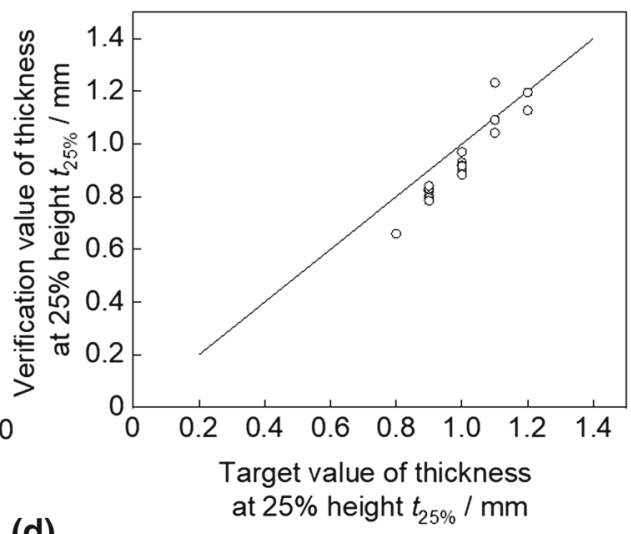

(d)

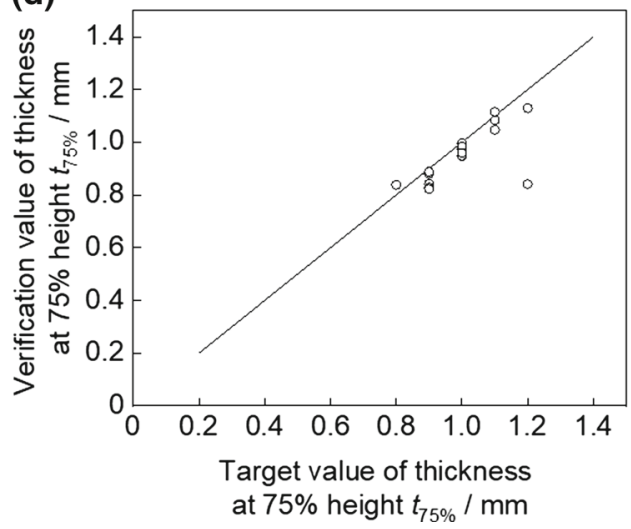

a large height and small thickness, the prediction data deviated from the target value, and the specimens were fractured under these conditions. This might be due to the excessive deviation between the target values and training dataset values. It is highly probable that the model does not have a significantly high extrapolation ability. An improvement in the extrapolation ability is recommended for future work.

\section{Evaluation of effects of path parameters on thickness of workpiece}

This section discusses the effective parameters for controlling the thickness of a workpiece. The model for illustrating the effect of the path parameters on the thickness distribution of cylindrical cups was developed using the seven input parameters and five output parameters $h, t_{25}, t_{50 \%}, t_{75} \%$, and $r_{\mathrm{p}}$ for the data of groups $\mathrm{A}, \mathrm{B}$, and $\mathrm{C}$. The prediction data for the height and thickness under the seven input data patterns were obtained to show the effect of each parameter on the thickness $t_{25}, t_{50 \%}$, and $t_{75 \%}$. In each pattern, one parameter had even interval values in the range between the minimum and maximum of the training data (groups A, $\mathrm{B}$, and $\mathrm{C}$ ), and the other six fixed parameters used the average value of each training data. The average thickness $\bar{t}$ was calculated from the height of the cup $h$ using the following equation, assuming a constant volume:

$$
\left(\frac{d_{\mathrm{blank}}}{2}\right)^{2} \pi t_{0}=\left(\frac{d_{\text {mandrel }}}{2}\right)^{2} \pi t_{0}+d_{\text {mandrel }} \pi h \bar{t},
$$

where $d_{\text {blank }}, \mathrm{d}_{\text {mandrel }}$, and $t_{0}$ are the diameters of the blank disk and mandrel, and the thickness of the blank disk, respectively.

Figure 9 shows the evolution of the thicknesses $t_{25}, t_{50 \%}$, $t_{75 \%}$, and $\bar{t}$ with increasing path parameters. The thickness was predicted by assigning seven input data patterns to the ANN model. Each pattern included one variable path parameter and six fixed parameters. The thickness increased with an increase in $y_{\mathrm{p} \text {-end }}, \alpha_{0}$, and $p_{\text {feed }}$ but decreased with an increase in $x_{\mathrm{p} \text {-start }}$ and $\Delta x_{\mathrm{p}}$. The effects of $n_{\mathrm{p}}$ and $x_{\mathrm{p} \text {-end }}$ on the thickness varied with the measured thickness position. The thickness $t_{25 \%}$ and $\bar{t}$ decreased with increasing $n_{\mathrm{p}}$, whereas $t_{50 \%}$ and $t_{75 \%}$ indicated a convex-type distribution against $n_{\mathrm{p}}$. Further, $t_{50 \%}$ and $t_{75 \%}$ increased with increasing $x_{\mathrm{p} \text {-end }}$, whereas $t_{25 \%}$ and $\bar{t}$ indicated a concave type distribution against the $x_{\mathrm{p}-\mathrm{end}}$. The thickness changed significantly when $\Delta x_{\mathrm{p}}$ was varied.

According to Fig. 9, which shows the effect of each parameter on the thickness $\left(t_{25 \%}, t_{50 \%}, t_{75} \%\right.$, and $\left.\bar{t}\right)$, the mechanism of thinning workpieces using various path parameters was 
(a)

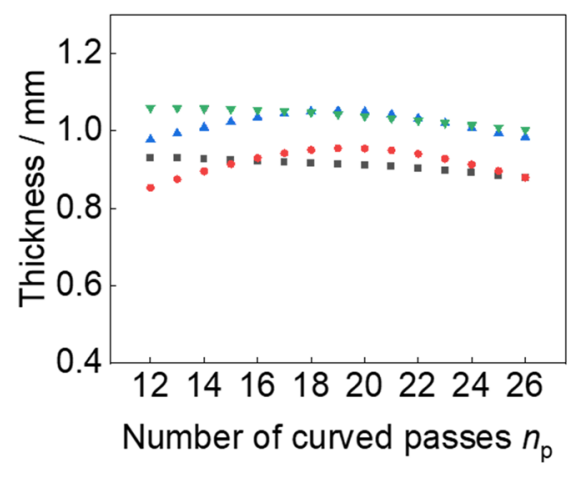

(d)

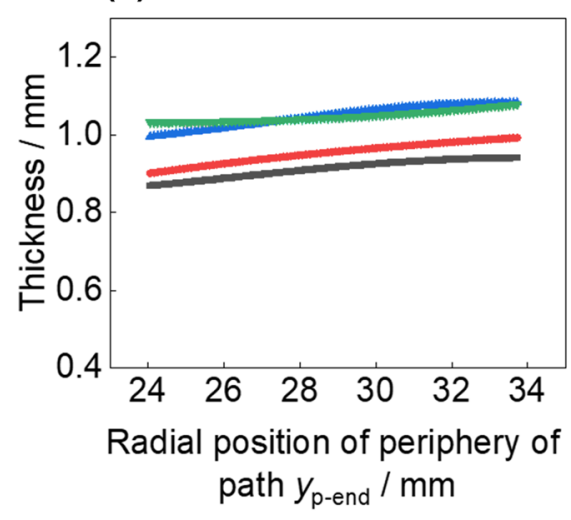

(f)

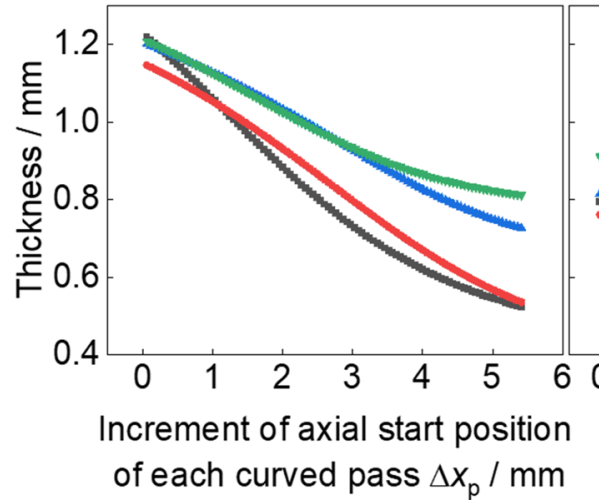

(b)

(c)

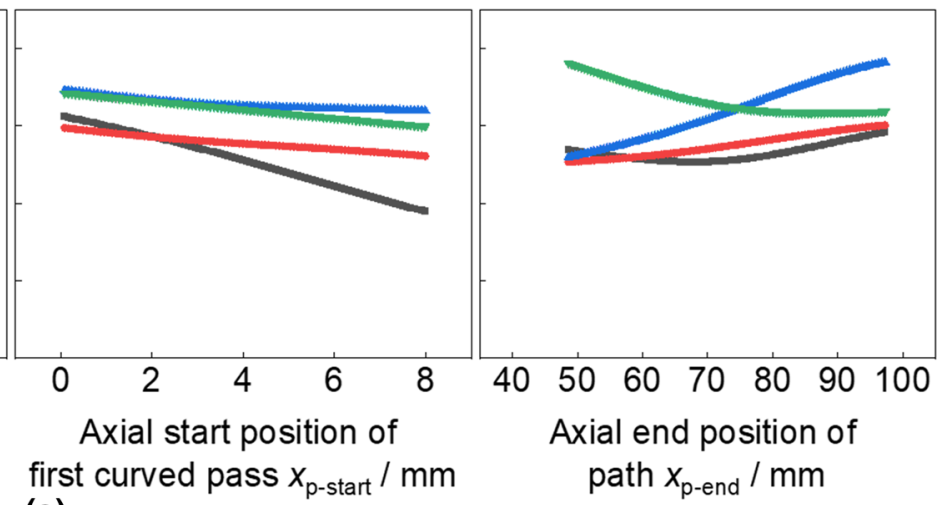

(e)
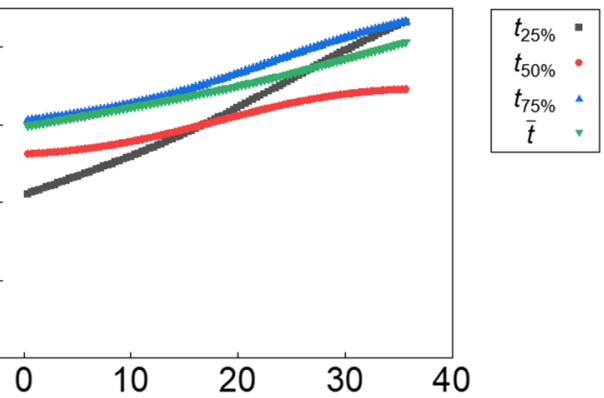

(g)

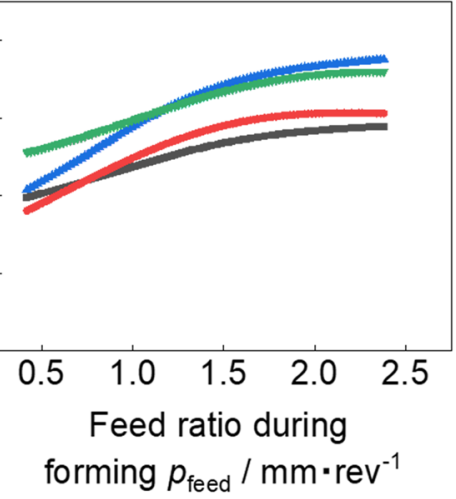

Fig. 9 Relationship between each path parameter and thickness $\left(t_{25 \%}, t_{50 \%}, t_{75 \%}\right.$, and $\left.\bar{t}\right)$

interpreted as follows. When the $y_{\mathrm{p} \text {-end }}$ or $x_{\mathrm{p} \text {-end }}$ was small, a flange was formed because the edge of the path did not reach the edge of the workpiece. Thus, the workpiece was pulled in its radial direction in the area between the mandrel corner and roller, resulting in thinning. The mechanism of thinning by decreasing $\alpha_{0}$ was similar to that described above. The small $\alpha_{0}$ allowed the flange of the workpieces to bend back toward the roller during forming, resulting in an increase in the radial directional stress between the mandrel corner and roller and thinning of the workpieces. Russo et al. (2021) investigated the effect of the roller path on the shape of a workpiece using a haptic scanning system to capture the skill of hand spinners.
They found that the spinners were careful not to trigger the flipping-back of the material, which causes radial directional stretching. When $x_{\mathrm{p} \text {-start }}$ or $\Delta x_{\mathrm{p}}$ was large, the workpiece was shear-spun in a straight path, and its thickness decreased. The thickness $t_{25 \%}$ decreased significantly with increasing $x_{\mathrm{p} \text {-start }}$ and $\Delta x_{\mathrm{p}}$ because the measurement position of $t_{25 \%}$ was near the straight path area. Sugita and Arai (2015) reported the same tendency: the thickness of a workpiece decreased with increasing $\Delta x_{\mathrm{p}}$. Similar to the results reported by Essa and Hartley (2009), the thickness increased with increasing $p_{\text {feed }}$. This was due to an increase in the circumferential compressive stress, which generated a compressive deformation. In 
(a)
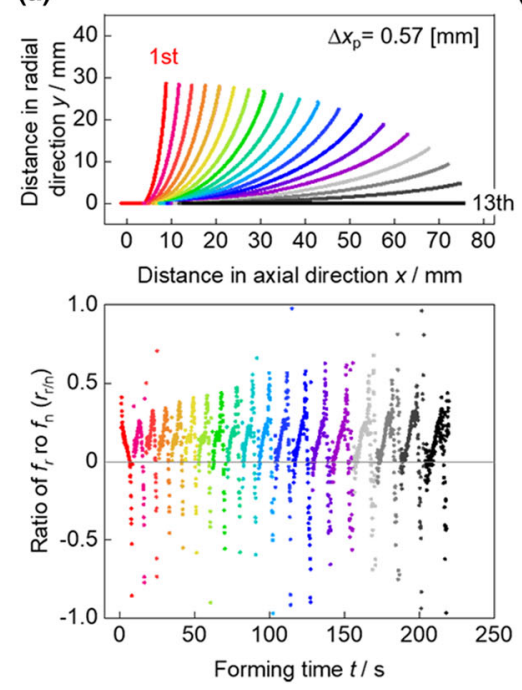

(b)
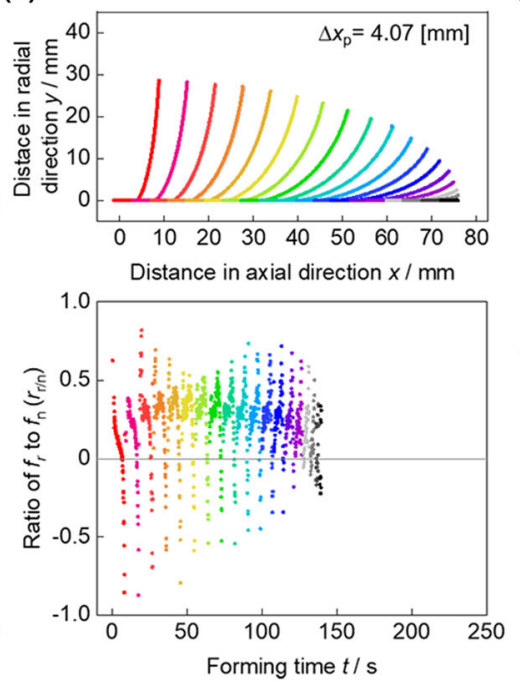

(c)

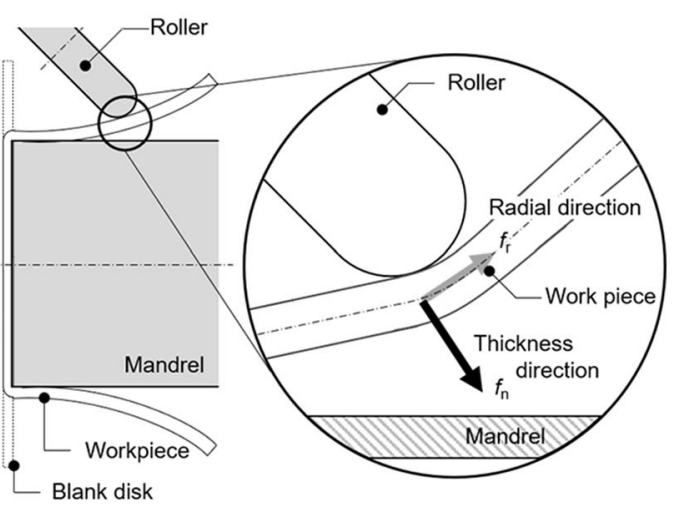

Fig. 10 Ratio of forming force in radial direction to force in thickness direction for $\mathbf{a}$ small $\Delta x_{\mathrm{p}}\left(\Delta x_{\mathrm{p}}=0.57\right)$ and $\mathbf{b}$ large $\Delta x_{\mathrm{p}}\left(\Delta x_{\mathrm{p}}=4.07\right)$

this reference, the circumferential compressive stress is represented as the tangential compressive stress. The change in thickness with increasing $n_{\mathrm{p}}$ was small compared to that of the other parameters.

The effects of the path parameters on the thickness distribution can be summarized as follows: the parameter $\Delta x_{\mathrm{p}}$ had the greatest influence on the thickness distribution, followed by $\alpha_{0}, p_{\text {feed }}, x_{\mathrm{p} \text {-start }}$, and $x_{\mathrm{p} \text {-end }}$. In contrast, the influence of $n_{\mathrm{p}}$ is small. In this study, the effect of the $y_{\mathrm{p} \text {-end }}$ was not conspicuous because the $y_{\mathrm{p} \text {-end }}$ was assigned too large to not form a flange.

From the above conjecture of deformation mechanisms, the tensile deformation in the radial direction between the mandrel corner and roller by forming a flange, and the radial tensile deformation where the material is shear-spun significantly affects the thickness variation. This tendency was experimentally demonstrated by Gondo et al. (2021). They clarified that a large ratio of the forming force in the radial direction to the force in the thickness direction generates a decrease in thickness. Figure 10 shows the path of the roller nose center and ratio as a function of forming passed time when $\Delta x_{\mathrm{p}}$ was 0.57 and 4.07 ; the other parameters were fixed. The ratio for $\Delta x_{\mathrm{p}}=4.07$ varied at a higher level compared to that for $\Delta x_{\mathrm{p}}=0.57$. These results satisfied the above relationship between the thickness and the ratio of the force in the radial direction to the force in the thickness direction. In other words, controlling the parameters that work in stretching materials in the radial direction is important for controlling the thickness during metal spinning.

In summary, this study revealed (1) the high applicability of ANN to metal spinning and (2) the effectiveness of the iterative solution in obtaining the path parameters under which the desired configuration of the workpiece can be achieved. This study further clarified that (3) controlling the path parameters that considerably affect the radial tensile deformation should be set appropriately to control the thickness distribution of a workpiece. This study constructed an ANN model in which the dimensions of the blank disk and material in training were the same as those in the prediction and validation, and succeeded in leading the optimization of the path parameters using the iterative solution of the ANN model. We consider that the ANN model will have to handle complicated variations in the factors related to the blank disk and mandrel in future work. One of example approaches is using a function composed of multiple parameters as an input parameter (Etesami et al. (2021)). It is worth to examine merit of constructing new parameters from the path parameters. Another example is application of high order ANN model. Zhao et al. (2017) investigated the possibility of using a high order ANN to model highly complex and dynamic relationship.

\section{Conclusions}

The main conclusions of this study are as follows:

1. The relationship between the path parameters in multipass conventional spinning and the spun workpiece configuration can be expressed using an ANN model.

2. The path parameters required to control the height and thickness distribution along the height can be determined using an iterative solution.

3. This study succeeded in obtaining spun workpieces with a constant thickness. 
4. Path parameters that exhibit significant effects on the radial tensile deformation significantly affect the thickness distribution of the workpiece. In this study, the most influential parameter was the increment in the axial start position for each curved pass.

\section{Appendix: Improvement of generalization capability of ANN using combination of orthogonal array of the Taguchi method and random offset}

\section{A-1. Design of experiments}

This study used design of experiments (DOE) and random offset to determine the experimental parameters for the training dataset to improve the generalization capability of the artificial neural network (ANN) model. DOE is a statistical methodology for the efficient analysis of experimental results with a large number of factors. In particular, the Taguchi method can significantly decrease the number of experiments required by assigning factors appropriately according to the orthogonal arrays (Taguchi, 1976).

For instance, the investigation of the effect of seven factors requires $2187\left(=3^{7}\right)$ experiments to completely cover the factor size with three levels: large, medium, and small. In contrast, the effects of the seven factors can be analyzed using the results of 18 experiments using the L18 orthogonal array (Table 3). This table consists of six factors with three levels and one factor with six levels. Kleiner et al. (2002) studied conventional spinning under the arrangement of parameters in accordance with the DOE and analyzed the factors causing wrinkling. Essa and Hartley (2010) used an orthogonal array to determine the process parameters in the finite element method (FEM) analysis of multi-pass conventional spinning. Trowsdale et al. (1998) investigated the effects of the number of training data on the accuracy of an ANN model for finite element analysis. Thus, it was concluded that experiments using DOE could achieve a higher accuracy under a small number of experiments in comparison with those using randomly assigned parameters. In addition, Ko et al. (1998) and Sanjari et al. (2009) established an ANN model using FEM simulation results that were analyzed under process parameters according to an orthogonal array.

The process parameters assigned using an orthogonal array are effectively distributed in a multidimensional parameter space to specify the effects of the process parameters on the processing results. However, each parameter value had only a few levels. Thus, each node in the input layer has limited discrete values. It is highly probable that the ANN model cannot be effectively trained, particularly for the function of intermediate values. In addition, the information entropy of
Table 3 Orthogonal array L18

\begin{tabular}{llllllll}
\hline Experiments & \multicolumn{7}{l}{ Factors } \\
\cline { 2 - 7 } & 1 & 2 & 3 & 4 & 5 & 6 & 7 \\
\hline 1 & 0 & 0 & 0 & 0 & 0 & 0 & 0 \\
2 & 0 & 1 & 1 & 1 & 1 & 1 & 1 \\
3 & 0 & 2 & 2 & 2 & 2 & 2 & 2 \\
4 & 1 & 0 & 0 & 1 & 1 & 2 & 2 \\
5 & 1 & 1 & 1 & 2 & 2 & 0 & 0 \\
6 & 1 & 2 & 2 & 0 & 0 & 1 & 1 \\
7 & 2 & 0 & 1 & 0 & 2 & 1 & 2 \\
8 & 2 & 1 & 2 & 1 & 0 & 2 & 0 \\
9 & 2 & 2 & 0 & 2 & 1 & 0 & 1 \\
10 & 3 & 0 & 2 & 2 & 1 & 1 & 0 \\
11 & 3 & 1 & 0 & 0 & 2 & 2 & 1 \\
12 & 3 & 2 & 1 & 1 & 0 & 0 & 2 \\
13 & 4 & 0 & 1 & 2 & 0 & 2 & 1 \\
14 & 4 & 1 & 2 & 0 & 1 & 0 & 2 \\
15 & 4 & 2 & 0 & 1 & 2 & 1 & 0 \\
16 & 5 & 0 & 2 & 1 & 2 & 0 & 1 \\
17 & 5 & 1 & 0 & 2 & 0 & 1 & 2 \\
18 & 5 & 2 & 1 & 0 & 1 & 2 & 0 \\
\hline & & & & & & &
\end{tabular}

the training data may deteriorate owing to the low number of information bits input into the ANN model.

\section{A-2. Demonstration of improvement in generalization capability}

In this study, to overcome the disadvantage of limited levels of the orthogonal arrays, we attempted to vary the level of input parameters in the parameter space using partial randomization of the orthogonal array.

In the case of a typical orthogonal array wherein the parameter $p_{\mathrm{i}}$ corresponds to the factor of $L$ levels of the table, $j=0,1, \ldots, L-1$, and the parameter $p_{\mathrm{i}}$ is calculated using Eq. (A-1).

$p_{i}=p_{i}^{M I N}+\left(p_{i}^{M A X}-p_{i}^{M I N}\right) \frac{j}{L-1}$

where $p_{\mathrm{i}}{ }^{\mathrm{MAX}}$ and $p_{\mathrm{i}}{ }^{\mathrm{MIN}}$ are the maximum and minimum values of the parameter $p_{\mathrm{i}}$, respectively. The parameter $p_{\mathrm{i}}$ can be calculated using Eq. (A-2), using partial randomization of the orthogonal array,

$p_{i}=p_{i}^{M I N}+\left(p_{i}^{M A X}-p_{i}^{M I N}\right) \frac{j+\gamma}{L}$,

where $\gamma$ is a uniform random number that ranges between 0 and 1 . The aforementioned assignment of parameter values can diversify the levels of the input parameters to the same 
Fig. 11 Accuracy comparison of ANN models using only the orthogonal array and partial randomization of orthogonal array for the Taguchi method: a RMSE and $\mathbf{b} R^{2}$

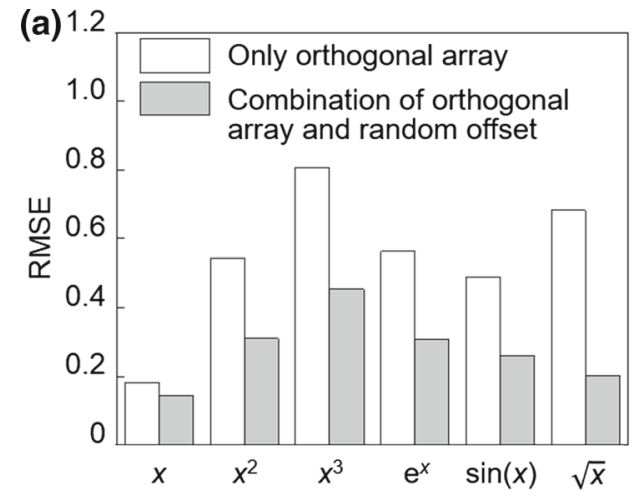

extent as the number of experiments without changing the range and order of levels in the input parameters.

To confirm the improvement in the generalization capability, this method was simulated using a computer program of the ANN model, which was programmed in the $\mathrm{C}$ language. The L18 orthogonal array (Table 3 ) was used, and the number of input data was 18 . The output function $f(\boldsymbol{p})$ was calculated using the input parameter $p_{\mathrm{i}}$, which was obtained using Eq. (A-1) or (A-2), ranging between 0 and 1 . The function $f(\boldsymbol{p})$ was calculated from six types of functions $g\left(p_{i}\right)$, as shown in Eq. (A-3) and (A-4).

$$
\begin{aligned}
& f(\boldsymbol{p})=\sum_{i=1}^{7} g\left(p_{i}\right) \\
& g\left(p_{i}\right)=p_{i}, p_{i}^{2}, p_{i}^{3}, e^{p_{i}}, \sin \pi p_{i}, \sqrt{p_{i}} .
\end{aligned}
$$

The ANN models were multilayer perceptrons (MLPs) with seven nodes in the input layer, seven nodes in the hidden layer, and one node in the output layer. The activation function was a sigmoid function. These models were trained using the back-propagation method for 5000 epochs using 18 training datasets. A total of 100 combinations of the input parameters were prepared using uniform random numbers ranging between 0 and 1 as the validation data. Subsequently, the true output values for validation were calculated according to Eqs. (A-3) and (A-4). The predicted values were calculated using the ANN models and compared to the validation output values.

The ANN models were evaluated using the root mean square error (RMSE) and coefficient of determination $\left(R^{2}\right)$ in Eqs. (6) and Eq. (7), respectively, and Fig. 11 shows the RMSE and $R^{2}$ results. In the case of the models using the randomized orthogonal array, the RMSE was smaller and $R^{2}$ was larger than those in the models using only the orthogonal array. In particular, the $R^{2}$ for the orthogonal array showed negative values for $g\left(p_{i}\right)=p_{i}^{3}, \sqrt{p_{i}}$. These data suggests that limited levels of input parameters degrade the prediction accuracy.

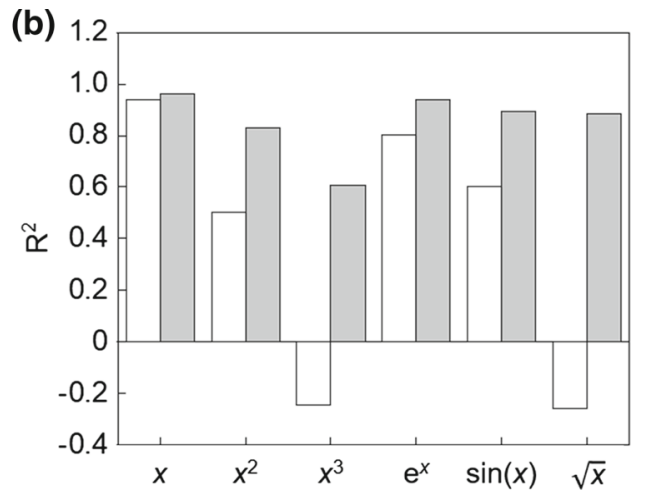

Supplementary Information The online version contains supplementary material available at https://doi.org/10.1007/s10845-021-01886-w.

Author contributions Conceptualization: Hirohiko Arai; Methodology: Shiori Gondo and Hirohiko Arai; Formal analysis and investigation: Shiori Gondo and Hirohiko Arai; Writing-original draft preparation: Shiori Gondo and Hirohiko Arai; Writing-review and editing: Shiori Gondo and Hirohiko Arai.

Funding No funding was received for conducting this study.

\section{Declarations}

Conflict of interest The authors have no conflicts of interest to declare that are relevant to the content of this article.

Open Access This article is licensed under a Creative Commons Attribution 4.0 International License, which permits use, sharing, adaptation, distribution and reproduction in any medium or format, as long as you give appropriate credit to the original author(s) and the source, provide a link to the Creative Commons licence, and indicate if changes were made. The images or other third party material in this article are included in the article's Creative Commons licence, unless indicated otherwise in a credit line to the material. If material is not included in the article's Creative Commons licence and your intended use is not permitted by statutory regulation or exceeds the permitted use, you will need to obtain permission directly from the copyright holder. To view a copy of this licence, visit http://creativecomm ons.org/licenses/by/4.0/.

\section{References}

Alsamhan, A., Ragab, A. E., Dabwan, A., Nasr, M. M., \& Hidri, L. (2019). Prediction of formation force during single-point incremental sheet metal forming using artificial intelligence techniques. PLoS ONE, 14(8), e0221341. https://doi.org/10.1371/ journal.pone. 0221341

Ashhab, M. S., Breitsprecher, T., \& Wartzack, S. (2014). Neural network based modeling and optimization of deep drawing-extrusion combined process. Journal of Intelligent Manufacturing, 25, 77-84. https://doi.org/10.1007/s10845-012-0676-z

Barletta, M., Gisario, A., \& Guarino, S. (2009). Hybrid forming process of AA 6108 T4 thin sheets: Modelling by neural network solutions. Proceedings of the Institution of Mechanical Engineers, Part B: Journal of Engineering Manufacture, 223(5), 535-545. https://doi. org/10.1243/09544054jem1218 
Baseri, H., Rahmani, B., \& Bakhshi-Jooybari, M. (2012). Predictive models of the spring-back in the bending process. Applied Artificial Intelligence, 26(9), 862-877. https://doi.org/10.1080/08839514. 2012.726155

Belfiore, N. P., Ianniello, F., Stocchi, D., Casadei, F., Bazzoni, D., Finzi, A., Carra, S., González, J. R., Llanos, J. M., Heikkila, I., Peñalba, F., \& Gómez, X. (2007). A hybrid approach to the development of a multilayer neural network for wear and fatigue prediction in metal forming. Tribology International, 40(10-12), 1705-1717. https://doi.org/10.1016/j.triboint.2007.01.008

Bingöl, S., \& Kilıçgedik, H. Y. (2018). Application of gene expression programming in hot metal forming for intelligent manufacturing. Neural Computing and Applications, 30, 937-945.

Breiman, L. (1996). Bagging predictors. Machine Learning, 24, 123-140. https://doi.org/10.1007/BF00058655

Chen, S. W., Zhan, M., Gao, P. F., Ma, F., \& Zhang, H. R. (2021). A new robust theoretical prediction model for flange wrinkling in conventional spinning. Journal of Materials Processing Technology, 288, 116849. https://doi.org/10.1016/j.jmatprotec.2020.116849

Chi, X., \& Han, S. (2019). Effects of servo tensile test parameters on mechanical properties of medium-Mn steel. Materials, 12(22), 3793. https://doi.org/10.3390/ma12223793

El-Khabeery, M. M., Fattouh, M., El-Sheikh, M. N., \& Hamed, O. A. (1991). On the conventional simple spinning of cylindrical aluminium cups. International Journal of Machine Tools and Manufacture, 31(2), 203-219. https://doi.org/10.1016/08906955(91)90005-N

Essa, K., \& Hartley, P. (2009). Numerical simulation of single and dual pass conventional spinning processes. International Journal of Material Forming, 2, 271-281. https://doi.org/10.1007/s12289009-0602-x

Essa, K., \& Hartley, P. (2010). Optimization of conventional spinning process parameters by means of numerical simulation and statistical analysis. Proceedings of the Institution of Mechanical Engineers, Part B: Journal of Engineering Manufacture, 224(11), 1691-1705. https://doi.org/10.1243/09544054JEM1786

Etesami, D., Zhang, W. J., \& Hadian, M. (2021). A formation-based approach for modeling of rate of penetration for an offshore gas field using artificial neural networks. Journal of Natural Gas Science and Engineering, 95, 104104. https://doi.org/10.1016/j.jngse. 2021.104104

Freund, Y., \& Schapire, R. E. (1997). A decision-theoretic generalization of on-line learning and an application to boosting. Journal of Computer and System Sciences, 55(1), 119-139. https://doi.org/ 10.1006/jcss.1997.1504

Göbel, R., Kleiner, M., \& Henkenjohann, N. (2005). New approach for process planning and optimization in sheet metal spinning. Advanced Materials Research, 6-8, 493-500. https://doi.org/10. 4028/www.scientific.net/AMR.6-8.493

Gondo, S., Arai, H., Kajino, S., \& Nakano, S. (2020). Texture evolution of a rolled aluminum sheet in multi-pass conventional spinning. Metals, 10(6), 793. https://doi.org/10.3390/met10060793

Gondo, S., Arai, H., Kajino, S., \& Nakano, S. (2021). Evolution of strain state of a rolled aluminum sheet in multi-pass conventional spinning. Journal of Manufacturing Science and Engineering, 143(6), 061011. https://doi.org/10.1115/1.4049476

Hansen, L. K., \& Salamon, P. (1990). Neural network ensembles. IEEE Transactions on Pattern Analysis and Machine Intelligence, 12(10), 993-1001. https://doi.org/10.1109/34.58871

Hartmann, C., Opritescu, D., \& Volk, W. (2019). An artificial neural network approach for tool path generation in incremental sheet metal free-forming. Journal of Intelligent Manufacturing, 30, 757-770. https://doi.org/10.1007/s10845-016-1279-x

Hayama, M., \& Murota, T. (1963). Study of metal spinning (1st report): Cylindrical shapes. Journal of the Japan Society for Precision
Engineering, 29(5), 369-376. https://doi.org/10.2493/jjspe1933. 29.369

Hayama, M., \& Tago, A. (1968). Fracture of cone-wall in shear spinning: Investigation into spinnability of aluminum sheet. Journal of the Japan Society for Technology of Plasticity, 9(84), 37-45.

Hussaini, S. M., Singh, S. K., \& Gupta, A. K. (2014). Experimental and numerical investigation of formability for austenitic stainless steel 316 at elevated temperatures. Journal of Materials Research and Technology, 3(1), 17-24. https://doi.org/10.1016/j.jmrt.2013. 10.010

Jafari, M., Lotfi, M., Ghaseminejad, P., Roodi, M., \& Teimouri, R. (2015). Numerical control and optimization of springback in Lbending of magnesium alloy through $\mathrm{FE}$ analysis and artificial intelligence. Transactions of the Indian Institute of Metals, 68(5), 969-979. https://doi.org/10.1007/s12666-015-0535-7

Jamli, M. R., \& Farid, N. M. (2019). The sustainability of neural network applications within finite element analysis in sheet metal forming: A review. Measurement, 138, 446-460. https://doi.org/10.1016/j. measurement.2019.02.034

Jiang, S., Ren, Z., Xue, K., \& Li, C. (2008). Application of BPANN for prediction of backward ball spinning of thin-walled tubular part with longitudinal inner ribs. Journal of Materials Processing Technology, 196(1-3), 190-196. https://doi.org/10.1016/j.jmatprotec. 2007.05.034

Kalpakcioglu, S. (1961). A study of shear-spinnability of metals. Journal of Engineering for Industry Transaction of ASME B, 83(4), 478-484. https://doi.org/10.1115/1.3664570

Kleiner, M., Göbel, R., Kantz, H., Klimmek, Ch., \& Homberg, W. (2002). Combined methods for the prediction of dynamic instabilities in sheet metal spinning. CRIP Annals Manufacturing Technology, 51(1), 209-214. https://doi.org/10.1016/S00078506(07)61501-7

Ko, D. C., Kim, D. H., Kim, B. M., \& Choi, J. C. (1998). Methodology of preform design considering workability in metal forming by the artificial neural network and Taguchi method. Journal of Materials Processing Technology, 80-81, 487-492. https://doi.org/10.1016/ S0924-0136(98)00152-6

Kobayashi, S. (1963). Instability in conventional spinning of cones. Journal of Engineering for Industry Transaction of ASME B, 85(1), 44-48. https://doi.org/10.1115/1.3667585

Kong, Q., Yu, Z., Zhao, Y., Wang, H., \& Lin, Z. (2017). Theoretical prediction of flange wrinkling in first-pass conventional spinning of hemispherical part. Journal of Materials Processing Technology, 246, 56-68. https://doi.org/10.1016/j.jmatprotec.2016.07.031

Kurtaran, H. (2008). A novel approach for the prediction of bend allowance in air bending and comparison with other methods. The International Journal of Advanced Manufacturing Technology, 37, 486-495. https://doi.org/10.1007/s00170-007-0987-y

Lambiase, F., Di Ilio, A., \& Paoletti, A. (2016). Productivity in multipass laser forming of thin AISI 304 stainless steel sheets. The International Journal of Advanced Manufacturing Technology, 86, 259-268. https://doi.org/10.1007/s00170-015-8150-7

Liu, J. H., Yang, H., \& Li, Y. Q. (2002). A study of the stress and strain distributions of first-pass conventional spinning under different roller-traces. Journal of Materials Processing Technology, 129(1-3), 326-329. https://doi.org/10.1016/S09240136(02)00682-9

Mandal, S., Sivaprasad, P. V., \& Dube, R. K. (2007). Modeling microstructural evolution during dynamic recrystallization of alloy D9 using artificial neural network. Journal of Materials Engineering and Performance, 16(6), 672-679. https://doi.org/10.1007/ s11665-007-9098-z

Merayo, D., Rodríguez-Prieto, A., \& Camacho, A. M. (2020). Prediction of mechanical properties by artificial neural networks to characterize the plastic behavior of aluminum alloys. Materials, 13(22), 5227. https://doi.org/10.3390/ma13225227 
Nagargoje, A., Kankar, P. K., Jain, P. K., \& Tandon, P. (2021). Application of artificial intelligence techniques in incremental forming: A state-of-the-art review. Journal of Intelligent Manufacturing. https://doi.org/10.1007/s10845-021-01868-y

Pathak, K. K., Panthi, S., \& Ramakrishnan, N. (2005). Application of neural network in sheet metal bending process. Defence Science Journal, 55(2), 125-131. https://doi.org/10.14429/dsj.55.1976

Poshal, G., \& Ganesan, P. (2008). An analysis of formability of aluminium preforms using neural network. Journal of Materials Processing Technology, 205(1-3), 272-282. https://doi.org/10. 1016/j.jmatprotec.2007.11.107

Quigley, E., \& Monaghan, J. (2000). Metal forming: An analysis of spinning processes. Journal of Materials Processing Technology, 103(1), 114-119. https://doi.org/10.1016/S0924-0136(00)003940

Quigley, E., \& Monaghan, J. (2001). Using a finite element model to study plastic strains in metal spinning. In: Proceedings of 9th International Conference on Sheet Metal, pp. 255-262.

Quigley, E., \& Monaghan, J. (2002). The finite element modelling of conventional spinning using multi-domain models. Journal of Materials Processing Technology, 124(3), 360-365. https://doi. org/10.1016/S0924-0136(02)00259-5

Russo, I. M., Cleaver, C. J., \& Allwood, J. M. (2021). Seven principles of toolpath design in conventional metal spinning. Journal of Materials Processing Technology, 294, 117131. https://doi.org/10. 1016/j.jmatprotec.2021.117131

Sanjari, M., Karimi Taheri, A., \& Movahedi, M. R. (2009). An optimization method for radial forging process using ANN and Taguchi method. The International Journal of Advanced Manufacturing Technology, 40(7-8), 776-784. https://doi.org/10.1007/s00170008-1371-2

Sebastiani, G., Brosius, A., Ewers, R., Kleiner, M., \& Klimmek, C. (2006). Numerical investigation on dynamic effects during sheet metal spinning by explicit finite-element-analysis. Journal of Materials Processing Technology, 177(1-3), 401-403. https:// doi.org/10.1016/j.jmatprotec.2006.04.080

Sebastiani, G., Brosius, A., Homberg, W., \& Kleiner, M. (2007). Process characterization of sheet metal spinning by means of finite elements. Key Engineering Materials, 344, 637-644.

Srivastava, S., Srivastava, K., Sharma, R. S., \& Raj, K. H. (2004). Modelling of hot closed die forging of an automotive piston with ANN for intelligent manufacturing. Journal of Scientific and Industrial Research, 63, 997-1005.

Sugita, Y., \& Arai, H. (2015). Formability in synchronous multipass spinning using simple pass set. Journal of Materials Processing Technology, 217, 336-344. https://doi.org/10.1016/j.jmatprotec. 2014.11.017
Taguchi, G. (1976). Design of experiments. Maruzen. (in Japanese).

Trowsdale, A. J., Usherwood, T. W., Wadsworth, J. E. J., Patel, M., \& Farrugia, D. C. J. (1998). Neural networks for providing 'on-line' access to discretised modelling techniques. Journal of Materials Processing Technology, 80-81(1), 475-480. https://doi.org/10. 1016/S0924-0136(98)00150-2

Trzepieciński, T., \& Lemu, H. G. (2020). Improving prediction of springback in sheet metal forming using multilayer perceptronbased genetic algorithm. Materials, 13(14), 3129. https://doi.org/ 10.3390/ma13143129

Urata, S., Takada, A., \& Sekiya, A. (2001). Application of new ensemble learning method for the regression analysis: Arcing_RA. Journal of Computer Aided Chemistry, 2, 70-78. https://doi.org/10.2751/ jcac. 2.70

Viswanathan, V., Kinsey, B., \& Cao. J. (2003). Experimental implementation of neural network springback control for sheet metal forming. Journal of Engineering Materials and Technology, 125(2), 141-147. https://doi.org/10.1115/1.1555652

Wang, L., \& Long, H. (2011a). A study of effects of roller path profiles on tool forces and part wall thickness variation in conventional metal spinning. Journal of Materials Processing Technology, 211, 2140-2151. https://doi.org/10.1016/j.jmatprotec.2011.07.013

Wang, L., \& Long, H. (2011b). Investigation of material deformation in multi-pass conventional metal spinning. Materials and Design, 32(5), 2891-2899. https://doi.org/10.1016/j.matdes.2010.12.021

Wang, L., \& Long, H. (2013). Roller path design by tool compensation in multi-pass conventional spinning. Materials and Design, 46, 645-653. https://doi.org/10.1016/j.matdes.2012.10.048

Xia, Q, Shima, S., Kotera, H., \& Yasuhuku, D. (2005). A study of the one-path deep drawing spinning of cups. Journal of Materials Processing Technology, 159(3), 397-400. https://doi.org/10.1016/ j.jmatprotec.2004.05.027

Yamanaka, A., Kamijyo, R., Koenuma, K., Watanabe, I., \& Kuwabara, T. (2020). Deep neural network approach to estimate biaxial stressstrain curves of sheet metals. Materials and Design, 195, 108970. https://doi.org/10.1016/j.matdes.2020.108970

Zhan, M., Yang, H., Zhang, J. H., Xu, Y. L., \& Ma, F. (2006). Research on variation of stress and strain field and wall thickness during cone spinning. Materials Science Forum, 532-533, 149-152.

Zhao, Y., Sun, J., Gupta, M. M., Moody, W., Laverty, W. H., \& Zhang, W. (2017). Developing a mapping from affective words to design parameters for affective design of apparel products. Textile Research Journal, 87(18), 2224-2232. https://doi.org/10. $1177 / 0040517516669072$

Publisher's Note Springer Nature remains neutral with regard to jurisdictional claims in published maps and institutional affiliations. 